\title{
The role of probiotics on the roadmap to a healthy microbiota: a symposium report
}

\author{
Stacey Lockyer ${ }^{1}$ (D), Marisol Aguirre ${ }^{2}$, Louise Durrant ${ }^{3},{\text { Bruno } \operatorname{Pot}^{2} \text { and Kaori Suzuki }}^{2 \star}$ (D) \\ ${ }^{1}$ British Nutrition Foundation, London, United Kingdom \\ ${ }^{2}$ Yakult Europe B.V., Almere, The Netherlands \\ ${ }^{3}$ Yakult UK Limited, South Ruislip, United Kingdom \\ *Corresponding author. Email: KSuzuki@yakulteurope.com
}

(Received 16 January 2020; revised 23 April 2020; accepted 1 May 2020)

\begin{abstract}
The ninth International Yakult Symposium was held in Ghent, Belgium in April 2018. Keynote lectures were from Professor Wijmenga on using biobanks to understand the relationship between the gut microbiota and health; and Professor Hill on phage-probiotic interactions. Session one included talks from Professor Plösch on epigenetic programming by nutritional and environmental factors; Professor Wilmes on the use of "omics" methodologies in microbiome research and Professor Rescigno on the gut vascular barrier. Session two explored the evidence behind Lactobacillus casei Shirota with Dr Nanno explaining the plasticity in immunomodulation that enables the strain to balance immune functions; Dr Macnaughtan outlining its potential therapeutic use in cirrhosis and Professor Nishida detailing effects in subjects under stress. The third session saw Professor Marchesi describing that both the host genes and the gut microbiota can play a role in cancer; Professor Bergheim highlighting crosstalk between the gut and the liver and Professor Cani describing the relationship between the gut microbiota and the endocrine system. The final session explored probiotic mechanisms, with Professor Lebeer dissecting the challenges in conducting mechanistic studies; Professor Wehkamp describing the mucosal defence system and Professor Van de Wiele detailing methods for modelling the gut microbiota in vitro.
\end{abstract}

Keywords: Probiotics; L. casei Shirota; health; gut microbiota

\section{Introduction}

The ninth International Yakult Symposium, entitled "The Role of Probiotics on the Roadmap to a Healthy Microbiota" was held on 19th-20th April 2018 in Ghent, Belgium. This report summarises the talks given by a panel of international experts, who covered different aspects of microbiology, systems biology, immunology, genetics and research methodologies as well as health conditions such as metabolic and liver disease, cancer and stress.

\section{You and your microbes and the use of population biobanks to understand their intricate relationships}

Professor Cisca Wijmenga (University of Groningen, The Netherlands) set the scene for the meeting by outlining the complex ecosystem that is the gut microbiota, comprising bacteria, fungi and viruses. There are hundreds of different bacterial species in the gut (Wallace et al., 2011) and their DNA can now be

\footnotetext{
( The Author(s), 2020. Published by Cambridge University Press in assocition with The Nutrition Society. This is an Open Access article, distributed under the terms of the Creative Commons Attribution licence (http://creativecommons.org/licenses/by/4.0/), which permits unrestricted re-use, distribution, and reproduction in any medium, provided the original work is properly cited.
} 
studied via metagenomic sequencing, currently used to identify which bacterial strains are present, what kind of genes they harbour and their functional pathways (Chen et al., 2018).

The microbiota is extremely dynamic during the course of life. For example, the composition of the microbiota matures from birth towards an adult-like composition in the first 3 years of life and the specific bacteria that colonise the human body will be dependent on various environmental exposures (Chen et al., 2018). Serious perturbations (eg. antibiotic use) that occur in this community both during early life or later can lead to dysbiosis (ie. variation in composition, such as decreased diversity). However, the normal variation present in the gut microbiota, which factors can lead to dysbiosis and how the balance of the gut microbiota can be restored during dysbiosis is not yet fully understood. Dysbiosis has been implicated in diseases that manifest both within and outside the gut including autism, asthma, liver disease, skin disorders, type 2 diabetes, obesity and inflammation (Chen et al., 2018), but these relationships have mostly been reported from observational data and so it is not known whether dysbiosis is causal or occurs as a result of such diseases. If indeed there is causality, knowing which exact strains/species of bacteria contribute to disease, at what time and through which mechanisms, and how the gut microbiota can be modified to treat or prevent disease would be extremely useful, particularly in relation to chronic diseases due to the high proportion of individuals experiencing these during their lifetime.

Population-based cohort studies are useful in studying the gut microbiota and their collective set of genes (ie. microbiome) because they tend to be large in size and the data are collected in a standardised way, therefore interactions between different layers of data (eg. genetic, environmental, behavioural, social) can be examined to try to untangle relationships (Wijmenga and Zhernakova, 2018). Many different phenotypes can be described using "omics" data. Of particular use are longitudinal data which capture people before they have a disease, during the disease and afterwards. More than 160,000 people of the northern region of the Netherlands aged from 8 to 100 years have contributed to the LifeLines cohort study, a longitudinal biobank which began in 2005. Blood, urine, faeces and hair samples, plus a large variety of other data such as heart and lung function, lifestyle questionnaires and dietary information have been collected from the participants. More detailed information is held for a subset of $\sim 1,500$ people including multiomics data such as genotypes, transcriptomes, DNA methylation status, blood lipids, untargeted metabolites, proteins and characterisation of the gut microbiome using both 16S rRNA gene sequencing and metagenomics. This cohort is known as LifeLines DEEP (Tigchelaar et al., 2015) and one of the aims of this project is to identify factors that are associated with the composition of the gut microbiota. Two hundred and seven different factors such as blood lipids, diseases, medication, diet and host genetics have been examined. Simple profiling of faecal samples from 1,135 subjects demonstrates the high variability in the gut microbiota between individuals (Zhernakova et al., 2016), with less diversity considered as being less healthy for the host. What is clear is that the gut microbiota is personal and unique for every person. At present, however, what is meant by a "healthy" microbiota is not known because there is no uniform scoring system available. Overall, more than 100 factors have been estimated to contribute to microbiota variation or perturbation (Zhernakova et al., 2016). Strong correlations were observed with blood lipids [eg. levels of high-density lipoproteins and triglycerides were more strongly associated with the microbiota than with host genes (studied by metagenomics)], medication, smoking, diet, body mass index, stool consistency and many conditions including anaemia, irritable bowel syndrome (IBS) and cardiovascular events. Stool consistency (measured by the Bristol Stool Form Scale) and frequency of bowel movements had a strong association with the composition of the gut microbiota in this cohort (Falony et al., 2016). For example, the abundance of Firmicutes tended to be higher (and simultaneously Archaea tended to be lower) in individuals with more frequent bowel movements. However, it is worth mentioning that with respect to this particular association, the literature shows no clear consensus.

Data obtained in the same cohort suggest a striking effect of medication on the gut. In particular, commonly used drugs such as statins and antidepressants have been associated with lower diversity of the gut microbiota (Zhernakova et al., 2016). Furthermore, proton pump inhibitors (PPIs) have been linked with increased risk of Clostridioides difficile and Campylobacter infections (Imhann et al., 2017). 
In the Lifelines DEEP cohort, PPI use was associated with a $20 \%$ difference in the taxa that were typically present (Imhann et al., 2016). Bacteria that are normally only present in the oral cavity were now found in the gut of these individuals. This was presumably because the $\mathrm{pH}$ of the stomach is increased by the PPIs, reducing the acidic barrier between the oral cavity and the gut, hence increasing the risk of enteric infections. Diet was also found to be a major indicator of gut diversity among the subjects and some dietary components could be considered unfavourable as they were associated with decreased diversity (Zhernakova et al., 2016). These include whole fat milk, beer, fizzy drinks, total intake of carbohydrates and high calorie diets; whereas fruits, vegetables, coffee, tea, red wine, buttermilk, cheese and yoghurt were associated with increased diversity. Streptococcus thermophilus, a traditional starter culture for the elaboration of yogurt, was highly abundant in the stools of daily consumers.

Professor Wijmenga finished by describing forthcoming extensions of her research. The LifeLinesNEXT cohort is expected to comprise 1,500 newborns that are the offspring of LifeLines participants. Data will be collected at multiple time points during the first year of life, hoping to shed light on the role of the virome 2016 in shaping the gut microbiome in its early development stage. Another project is the Netherlands Organ on a Chip Initiative (Netherlands Organ-on-Chip Initiative, 2018), a 10-year project centred around the recreation of organs-on-chips to look at, eg. the interaction between the gut microbiota, the gut epithelium or the liver using 3D microfluidics. The methodology used in this project aims to provide an environment that is more physiological than other in vitro methods to study tissue function in health and disease.

\section{The interaction of epigenetics and microbiota development}

Dr Torsten Plösch (The University Medical Center Groningen, The Netherlands) talked about the interaction of epigenetics and microbiota development, focusing on the long-term effects of nutrition in early life.

Dr Plösch cited the work of Dr David Barker who was one of the first to describe the relationship between undernutrition in utero and the proneness to diseases later in adult life. Barker was interested in why there were higher rates of cardiovascular disease (CVD) in some areas of the UK than others, and hypothesised that this was linked to early nutrition (Barker and Osmond, 1986). By analysing medical records, he found a correlation between birthweight and CVD risk with both low and high birthweight predicting a higher chance of developing CVD in later life. A similar U-shaped curve was found for type 2 diabetes (Barker et al., 1993). Studies looking into the Dutch Famine of 1944 demonstrated that starvation during pregnancy has detrimental effects on the long-term health of the offspring (Painter et al., 2005).

These observations are partially explained by epigenetics. Epigenetics can be illustrated by caterpillars and butterflies which have the same DNA but differently expressed according to the life stage, or by organ-specific differentiation of human cells which contain identical DNA (eg. skin cells, neurons, liver cells). Epigenetics can broadly be described as any modification that turns the expression of genes on and off, encompassing chromatin and DNA modifications and other transcription regulators (eg. DNA methylation at the CpG sites or acetylation of histones) (Greally, 2018).

Epigenetic status is influenced early on in development and then remains relatively stable. Dr Plösch hypothesises that the early environment leads to epigenomic modifications of key regulators of metabolism which influence lipid metabolism and CVD risk later in life. In a study looking at protein restriction, mice were fed either a normal diet (18\% protein) or a low protein diet (9\%) before becoming pregnant (van Straten et al., 2010 2009). Epigenetic characterisation of foetal livers revealed that 204 gene promoters were differentially methylated between the two groups. One of the most interesting genes was the liver X-receptor (LXR) which regulates lipid homeostasis. Under normal circumstances LXR is activated by oxysterols, cholesterol side products that stimulate adenosine triphosphate-binding cassette $(\mathrm{ABC})$ transporters to pump cholesterol out of the cell and increase lipogenesis, thereby esterifying cholesterol and protecting the cell against cholesterol build up (Steffensen and Gustafsson, 2004). Upon protein restriction, the LXR promoter is hypermethylated; therefore, expression goes down, as does the 
expression of target genes such as ABCA1 and fatty acid synthase genes 2009. This and the follow-up control experiments (van Straten et al., 2010) provide evidence that diet can induce changes in gene expression via epigenetic programming. Further experiments in mice suggest that epigenetic marks can persist beyond the immediate offspring. After 50\% calorie restriction during gestation, methylation of LXR in the liver (but not all organs) of second-generation mice was still altered and associated with abnormal lipid metabolism (Martínez et al., 2014).

Several animal and human studies have indicated that other major regulators of metabolism can be altered in an epigenetic way (eg. peroxisome proliferator-activated receptors, retinoid X receptor, glucocorticoid receptor, $\mathrm{ABC}$ transporters, pro-opiomelanocortin and insulin-like growth factor 2 receptor) and it is likely that a combination of these can be affected by the maternal diet, making the offspring more susceptible to the development of chronic disease (Jiménez-Chillarón et al., 2012). One of the proposed mechanisms is the availability of methyl groups for DNA methylation via the one carbon cycle, components of which are derived from the diet (eg. choline, betaine) or generated by gut bacteria (eg. vitamins B1, B2, B6, B9 and B12). It has also been discovered that docosahexaenoic acid has demethylating activity and $\alpha$-ketoglutarate can regulate DNA methylation. Acetylation of histones is also influenced by diet and by gut bacterial metabolites. For example, butyrate [and other short chain fatty acids (SCFA), albeit to a lesser extent] along with phenolic compounds, organic acids and vitamins B1 and B3, can potently block deacetylation leading to more active chromatin; while the production of sulphur compounds and vitamins B1, B5 and B7 cause other histone modifications (Mischke and Plösch, 2016).

As such, the correlations between the composition of the gut microbiota, diet and health or disease (eg. obesity) observed in both mice (Parks et al., 2013; Serino et al., 2012) and humans (David et al., 2013; Le Chatelier et al., 2013; Ridaura et al., 2013) could be due to epigenetic modifications (Mischke and Plösch, 2013). Causality, however, remains to be elucidated. For example, breastfed babies tend to have more bifidobacteria and ruminococci than formula fed babies (that have more streptococci and clostridia). Since folate (vitamin B9) can be produced by some bacteria including bifidobacteria, theoretically, breastfeeding stimulates folate production which could enhance DNA methylation; whereas formula feeding tends to increase butyrate, an important inhibitor of histone deacetylase (Mischke and Plösch, 2013). Therefore, changing the gut microbiota either through diet or drugs could alter the long-term physiology of the host by changing the availability of substrates for bacteria involved in DNA methylation (Mischke and Plösch, 2016).

In summary, nutrition during the first 1,000 days of life (including the gestational period) is especially important for epigenetic modifications and the early gut microbiota likely plays a significant role in this process. However, there are still many questions left to be answered: are there critical windows of susceptibility during development? Is the bacterial production of metabolites enough to induce epigenetic changes? Which tissues are most vulnerable to these modifications? These questions will likely be answered by ongoing and future research.

\section{Systems ecology of microbiome-human interactions: identifying which functions are key}

Professor Paul Wilmes (University of Luxembourg, Luxembourg) described the integrated multiomics approach that his team has developed to study microbial ecosystems.

High-throughput "omic" technologies unravel the complexity of the microbiome by providing high resolution qualitative and quantitative datasets on the genes (the metagenome), transcripts (the metatranscriptome), proteins (the metaproteome) and metabolites (the metabolome) present in microbial communities at specific points in space and time (Heintz-Buschart and Wilmes, 2018). These data can be integrated in a "multiomics" approach to reconstruct networks of constituent populations, deduce the interactions within the system (eg. gene regulatory networks, metabolic networks) and provide mechanistic insight into both biotic and abiotic factors shaping microbial communities (Muller et al., 2013).

Meaningful integration and analysis demand systematically generated data, which in turn requires robust sampling, sample preservation and biomolecular isolation methodologies (Roume et al., 2013). Professor Wilmes and his team developed a methodological flow for the sequential extraction and 
purification of all known biomolecular fractions from single unique samples (Kitano, 2001; Roume et al., 2012). This framework provides a standardised workflow to resolve keystone genes encoding key functionalities that have an effect on the entire ecosystem, keystone species that contribute to the stability of the microbial community, niche characteristics, and specialist and generalist lifestyle strategies. From this information hypotheses can be made around which species govern the success of the system and why or how proteins link to specific populations (if possible at a strain level). In addition, associations between biomolecules that may be indicative of previously unknown metabolic processes linked to specific community members can be uncovered (Roume et al., 2015). This knowledge should allow researchers to conduct molecular investigations on microbial communities with different compositions, compare the molecular profiles obtained and discover functional microbiota-specific biomolecular signatures, eg. substrates linked to different community members. The data can also be used to reconstruct metabolic networks, enabling, eg. to discern between "generalists" and "specialists". The former are able to thrive in a wide variety of environmental conditions, can use a variety of different resources and are favoured during environmental instability. The latter grow well only in a narrow range of environmental conditions, have a limited substrate usage and are likely to be favoured during environmental stability (Muller et al., 2014).

Perturbations, however, can occur in a microbial community, and analysing time points before and after such events can reveal how a disturbance can affect the whole network. In the context of the human gut, perturbations can be caused by drugs, especially antibiotics, or by dramatic changes in diet (Greenhalgh et al., 2016). Alterations of certain keystone species may have consequences for the whole system. For example, if a keystone species is eradicated, the network is "reset" by opening a significant niche for other organisms which may be opportunistic pathogens or beneficial microorganisms. This phenomenon is important for probiotics in terms of how these niches can be opened, offering a longterm foothold for these organisms within the gut (Quigley, 2010).

In such a setting, integrated multiomics have been used to study links between the gut microbiota and health and disease, eg. the understanding of the relationship between alterations in the microbiota and the functional consequences for type 1 diabetes (T1D). Integrated multiomic analyses were performed in 20 individuals from four Luxembourgian families of at least two generations with at least two cases of T1D (Heintz-Buschart et al., 2016). Faecal samples and dietary data were collected over a period of 24 months. Gut microbiota were compared to those without the disease in search for the most discriminative phenotype that could possibly link specific symptoms of the disease with the functions of certain microbial taxa. Individuality and family resemblance were observed at all the omic levels but there was no taxonomical signature for T1D. Rather, the faecal proteome was found to be more distinctive between healthy and diseased individuals. Enzymes secreted via the exocrine pancreas (such as alpha-amylases) involved in starch metabolism were reduced in the stools of individuals with T1D and different taxa (not necessarily abundant) were involved in this function. This observation was also correlated with reduced expression of key microbial enzymes involved in thiamine biosynthesis and glycolysis (Heintz-Buschart et al., 2016).

Professor Wilmes' group is also interested in changes following the early colonisation and succession of the microbiota during the first year of life from a functional point of view. They found that lipopolysaccharide (LPS) biosynthesis in the gut of infants born by caesarean section is different from those born through vaginal delivery and between infants who were smaller than average versus normal birthweight (Wampach et al., 2017). LPS extracted from vaginally delivered babies was found to be more immunostimulatory in early life than LPS extracted from babies delivered by caesarean section (Wampach et al., 2018). Integrated multiomics allowed linking of these functions to individual strains that are transferred from mother to neonate during vaginal delivery. The long-term functional repercussions of this for infants can be investigated using gut-on-a-chip methodologies, such as the modular microfluidics-based human-microbial coculture (HuMiX) model (Shah et al., 2016). Using these types of tools, multiomics approaches will offer exciting prospects for studying and unravelling interactions during probiotic administration. 
In his conclusion, Professor Wilmes emphasised that microbiota functionality is more important than composition, and in this context, probiotics should be thought of as "bags of functions", rather than a specific (combination of) species.

\section{The gut barrier and the immune system in health and disease}

\section{The barrier}

The coexistence between microbes and host demands a certain equilibrium which implies that: (i) the host must find the right balance to retain the microorganisms without the exacerbation of inflammatory tone and (ii) the microbial community does not represent a health threat in terms of composition and metabolic activity (Rescigno, 2017). Professor Maria Rescigno (Humanitas University, Italy) described the existence of a vascular barrier in the gut that protects the organism against the development of inflammation and the translocation of bacteria or their metabolic products into the liver and other organs.

Despite the crucial role of the microbiota in supporting the proper functioning of the body, most of the bacteria do not interact directly with the host. In the large intestine, microbes are spatially separated from the epithelium by a two-layered mucus. The outer layer serves as a unique microbial niche for distinct communities, whereas the inner layer constitutes a barrier in which glycoproteins organised in tight netlike structures and antimicrobial peptides reduce the presence of bacteria (Hooper and Macpherson, 2010). If microbes were to cross these layers, they would encounter the gut epithelium, a highly regulated semipermeable cellular barrier. However, mucosa-based protection against bacteria goes beyond the establishment of physical barriers. The mucosal immune system, an interconnected network of inductive sites [eg. mesenteric lymph nodes (mLNs)] and effector sites (eg. lamina propria), is able to selectively restrict the trafficking of exogenous substances and microorganisms into the blood (Spadoni et al., 2016). In a pathologic state, if bacteria translocate through the mucus layers and the epithelium, they are captured by the mLNs via the lymphatic vessels localised in the lamina propria and only microbes capable of systemic dissemination will reach the liver via the portal vein (Spadoni et al., 2017).

Anatomically, blood vessels are much closer to the epithelium as compared to the lymphatic vessels located deeper down (Bernier-Latmani et al., 2015; Cifarelli and Eichmann, 2019). Judging from this distribution, it is expected that bacteria would easily access the blood vessels. Yet, this is not the case most of the time. This suggests the existence of a differential trespassing of bacteria, but the precise mechanism behind the exclusion of gut microbes from the blood circulation is not well understood to date.

Professor Rescigno's research group postulated and demonstrated the existence of a gut vascular barrier (GVB) similar to the blood-brain barrier (BBB). While these two barriers share some structural and functional properties, as well as the involvement of the $\mathrm{Wnt} / \beta$-catenin signalling pathway in the control of the translocation of antigens, molecules, bacteria and cells into the blood stream, they differ in their permissiveness. The BBB avoids the uncontrolled migration of any substance in order to not only protect the brain parenchyma but also the central nervous system, whereas the GVB remains permeable to nutrients, facilitating its characteristic absorption function (Spadoni et al., 2016). For this reason, endothelial cells of the BBB do not have fenestrations whilst those of the GVB do.

Professor Rescigno's group demonstrated the existence of a GVB in mice by analysing the permissiveness of the gut vasculature using the dye fluorescein isothiocyanate (FITC)-dextran of different molecular sizes and examining the expression of plasmalemma vesicle-associated protein-1 (PV1), an endothelial cell-specific protein that makes up the diaphragms of the fenestrae of the capillaries in intestinal villi. Next, they orally administered Salmonella typhimurium, a pathogen that disseminates systemically in mice, to investigate whether damage of these structures would allow indiscriminate transit through the endothelium. This resulted in increased FITC-dextran leakage into the intestine, up-regulation of PV1 and liver damage, suggesting that the bacteria damaged the GVB allowing its dissemination via the portal blood to the liver (Spadoni et al., 2015). Further exploration proved that this was caused by a protein secreted by Salmonella that interferes with the Wnt/ $\beta$-catenin signalling pathway. No PV1 staining was observed when gut sections of healthy mice and humans were examined, 
providing evidence that a GVB is intact (Spadoni et al., 2015). Interestingly, Salmonella was also detected in Peyer's patches, mLNs and the spleen, indicating that the systemic spreading occurred by two different routes, namely the lymphatics and the portal vein.

The studies with S. typhimurium also highlighted the concept of the "leaky gut" and the existence of a gut-liver axis, illustrating the cascade of effects originally induced by a gut microbiota dysbiosis (ie. bloom of pathogens). An unbalanced microbiota can result in epithelial and endothelial damage, meaning that bacterial products can translocate to the liver, leading to chronic inflammation and ultimately to metabolic diseases such as cirrhosis (Wiest et al., 2014). The GVB tightly controls this axis and modifications at this barrier may be responsible for the development of liver damage.

Professor Rescigno subsequently demonstrated the existence of a GVB in the human gut and investigated whether the disruption of this barrier could be involved in the development of coeliac disease pathology. Intestinal biopsies analysed from these patients, who additionally had high transaminases levels, revealed high PV1 expression when compared to patients with normal transaminases (Spadoni et al., 2015). Increased transaminases levels are indicators of GVB modifications, presumably leading to liver damage.

In conclusion, there are two cellular barriers in the gut: the epithelium and the vascular endothelium. Although independent, they act in concert to protect not only the intestine but the whole organism from undesirable molecules and microorganisms. Disturbance of these barriers may underlie the pathophysiology of different health conditions.

\section{The immune system}

Professor Jan Wehkamp (University of Tübingen, Germany) talked about the relationships between probiotic bacteria and the host and their application in the development of therapies in combination with immunological or pharmaceutical agents for inflammatory and metabolic diseases.

He started his presentation by emphasising the importance of the intestinal mucosal defence system that keeps us free from inflammatory responses or infections, despite the fact that only one layer of cells separates the rest of our body from the trillions of bacteria present in the gut. As mentioned previously, the mucus layer is a reservoir for antimicrobial peptides (AMPs), eg. defensins and cathelicidins, among others. These peptides mainly act by disrupting the cell membrane of bacteria but can have other mechanisms of action. For example, $\alpha$-defensin 6 can form "nanonets" which physically prevent bacterial translocation (Raschig et al., 2017). Interestingly, the function of some of the AMPs can vary depending on local environment, eg. human $\beta$-defensin (hBD)- 1 is ubiquitously expressed on all cell surfaces and while it is not very active against bacteria in aerobic conditions, it exerts a potent antimicrobial effect in the anaerobic environment of the gut due to the reduction of disulphide bonds (Lehrer, 2011; Schroeder et al., 2011).

Some AMPs are secreted by Paneth cells in the small intestine and transgenic mice studies have demonstrated that the amount of defensins expressed in these cells is linked to the composition of the gut microbiota downstream from the small intestine (Salzman et al., 2009; Wehkamp et al., 2005). The involvement of commensal bacteria in physiological and/or pathological processes has been recognised beyond "infection", eg. being linked to inflammation and carcinogenesis. For instance, inflammatory bowel disease (IBD), previously considered to be an autoimmune disease, is now thought of as a disease linked to a deficient barrier function. In Crohn's disease, Paneth cells appear to play a central role especially when the inflammation affects the small intestine (Wehkamp and Stange, 2010). The different mechanisms causing different barrier dysfunctions promote and trigger what can be described as a secondary inflammatory cascade related to the presence and influx of commensal bacteria (Antoni et al., 2014).

More and more clinical treatments for cancer and IBD are combined with modulators of the gut microbiota composition (Sivan et al., 2015). In clinical trials in oncology, the clinical outcome of patients treated with checkpoint inhibitors correlates with gut microbial diversity and improved survival (Gopalakrishnan et al., 2018; Routy et al., 2018). Anti-tumour necrosis factor is widely prescribed for IBD patients and it has been reported that this treatment suppresses interleukin (IL)-22 binding protein, 
thus activating IL-22 (Pelczar et al., 2016), a strong stimulator of innate immunity at the epithelial level and an up-regulator of the antimicrobial peptide hBD-2 (Wolk et al., 2004). This is a rationale for developing drugs which target the mucosal-microbiota interface.

Intriguingly, many probiotics can produce AMPs themselves next to inducing the endogenous production of human defensins (Sassone-Corsi et al., 2016). Various strains including Escherichia coli Nissle, lactobacilli and the bacterial mixture VSL\#3, are consistent inducers of hBD-2 in intestinal epithelial cells, both in vitro and in vivo (Mondel et al., 2009; Schlee et al., 2007, 2008; Wehkamp et al., 2004). E. coli Nissle is unique among E. coli strains in its potency to induce hBD-2 and this effect is thought to be due to mechanisms involving flagella. However, other probiotic strains, not possessing flagella, can also induce hBD-2 but the reasons for this are not yet known (Wehkamp et al., 2004). Inducing hBD-2 appears to be detrimental to probiotics as their incubation with hBD-2 leads to cell death, although it is not clear why or how this occurs. This seemingly "suicidal" action may in part explain why probiotics need to be consumed daily.

This observation led Professor Wehkamp to study the impact of hBD-2 on the microbiota composition and abundance. He observed that the diversity of the gut microbiota increased in mice that received hBD- 2 orally but returned to baseline when the treatment stopped (Koeninger et al., 2018). This result and the fact that hBD- 2 improves barrier function, led to the hypothesis that hBD-2 could be useful to treat inflammation in colitis. Further experiments indeed showed that hBD-2 was as effective as steroids in mouse models of IBD (Koeninger et al., 2018). Clearly, this finding may be of value in patients as steroids have serious side effects upon long-term use. hBD-2 has also been tested in models of metabolic syndrome and non-alcoholic fatty liver diseases (NAFLDs), with positive results in relation to fat mass and weight control.

These findings illustrate that the modulation of gut microbiota composition to influence barrier function can work synergistically with drug therapies. Understanding the mechanism, eg. induction of protective factors such as IL-22, is crucial.

Having an intact antimicrobial barrier can protect from inflammation, not only in the gut but more widely, and could therefore play a role in the treatment of certain inflammation-related diseases such as asthma and metabolic syndrome.

\section{The gut and the liver: two of a kind?}

Professor Ina Bergheim (University of Vienna, Austria) further discussed the cross-talk between the gut and the liver, namely in the context of alcoholic and non-alcoholic fatty liver disease. Together with mucus, enterocytes, and endothelia in the intestine, the liver is one of the body's defence mechanisms against substances derived from food, drugs, exo- and endotoxins, xenobiotics and viral compounds. In this sense, the gut and the liver are "two organs that work in concert in a line of defence".

Approximately $80-90 \%$ of individuals with regular high alcohol consumption develop liver steatosis (fatty liver). While steatosis is reversible by stopping drinking alcohol, the organ damage can advance to steatohepatitis, fibrosis, cirrhosis and eventually to hepatocellular carcinoma in a more limited number of patients (Altamirano and Bataller, 2011).

Alcohol is energy rich, providing $7 \mathrm{kcal} / \mathrm{g}$. When consumed, it is metabolised by alcohol dehydrogenase (or cytochrome P450 2E1 during chronic consumption) to acetaldehyde, producing metabolites that are used to synthesise high energy substrates (eg. fat) and concomitantly generate reactive oxygen species (ROS) (Molina et al., 2014). For many years this was thought to explain the relationship between alcohol consumption, fatty liver and liver damage. However, the identification of elevated endotoxin levels in the blood of patients with alcoholic liver disease (ALD) suggested the involvement of a disrupted gut barrier, associated with the stage of ALD (Parlesak et al., 2000; Purohit et al., 2008). Experiments in animal models demonstrated that even acute exposure to ethanol (60-100 $\mathrm{min}$ ) increases gut barrier permeability (Rivera et al., 1998). Longer alcohol consumption (ie. 10 days) induced the expression of several toll-like receptors (TLRs) in liver tissues in rodents, indicating that not only bacterial endotoxin, but other toxins and viral compounds reach the liver under these conditions (Gustot et al., 2006). 
Preclinical and clinical studies have demonstrated that alcohol also alters the gut microbiota composition (Chen et al., 2011; Mutlu et al., 2012). In a rodent model of alcohol-induced liver injury, the administration of non-absorbed antibiotics decreased alcohol-induced damage as compared to a group that did not receive antibiotics (Adachi et al., 1995). Indeed, germ-free mice that received gut microbiota content from patients with more severe alcoholic hepatitis developed much more severe liver damage (Llopis et al., 2016). In another study, alcohol-fed mice receiving either a faecal transplant from mice resistant to alcohol-induced liver damage or mice fed with a pectin-enriched diet, did not develop steatosis or steatohepatitis, whereas control animals receiving neither treatment did develop liver disease (Ferrere et al., 2017). In patients with ALD, the composition of the small intestinal microbiota changes towards a more faecal type, with elevated endotoxin levels. Moreover, the faecal microbiota has been found to differ between regular drinkers with and without inflammation (Vassallo et al., 2015). Overall, ALD seems to be, at least in part, a disease of the gut, although more trials in humans are needed in this area to confirm this finding and to reveal the molecular mechanisms involved.

The global prevalence of non-alcoholic liver disease (NAFLD) is estimated at 24\% (Younossi, 2018); the main risk factors are obesity and insulin resistance, pointing to an effect of poor diet. Animal models suggest that a diet high in fat and fructose leads to overweight/obesity and worsens NAFLD (although the amounts consumed were much higher than those typically consumed by humans) (Sellmann et al., 2015). These effects are associated with a loss of tight junction proteins in the small intestine and with elevated bacterial endotoxin levels in portal plasma. The findings are similar to what is observed in models of ALD, suggesting that the gut is also involved in the development of NAFLD (Sellmann et al., 2015). In fact, mice consuming a "Western style diet" (high in fat, fructose and cholesterol) developed non-alcoholic steatohepatitis even in the absence of overnutrition, as compared to an isocaloric control diet. This observation suggests that the nutritional composition of the diet, rather than simple overnutrition, is a possible cause (Sellmann et al., 2015). Human studies have also shown that patients with different stages of NAFLD tend to have (i) increased endotoxin levels in the periphery (Nier et al., 2017), (ii) augmented gut permeability (Volynets et al., 2012), (iii) loss of tight junction proteins in the intestine (Miele et al., 2009) and (iv) upregulated TLRs in their liver tissue (Kanuri et al., 2015).

Regarding the involvement of the gut microbiota in NAFLD, mice fed drinking water enriched with fructose and given antibiotics had $\sim 50-60 \%$ reduced hepatic lipid accumulation and expression of TLRs, as compared to those receiving fructose-enriched drinking water alone (Bergheim et al., 2008; Wagnerberger et al., 2012). Furthermore, faecal microbiota transplants from animals consuming a control diet to animals with high fat diet-induced NAFLD attenuates steatohepatitis, restores tight junctions and lowers bacterial endotoxin significantly (Zhou et al., 2017). In humans, faecal microbiota and associated metabolites differ between children with or without NAFLD and vary with differing disease severity (Del Chierico et al., 2017).

The administration of probiotics in children and adults with NAFLD has improved markers of liver function (eg. alanine amino transferase, gamma-glutamyl transferase) in some studies (Aller et al., 2011; Nabavi et al., 2014; Vajro et al., 2011). However, further studies are needed to examine the possible benefits of probiotics in NAFLD (Sáez-Lara et al., 2016).

In summary, there is abundant evidence that dietary patterns and/or alcohol, the intestinal barrier and the gut microbiota contribute to the pathophysiology of ALD and NAFLD. Better understanding of these constituents is necessary to improve preventive and therapeutic measures.

\section{The gut and the endocrine system: a peaceful combination?}

Professor Patrice D. Cani (UCLouvain, Belgium) began his talk by highlighting the discovery of prebiotics, first described over 20 years ago (Gibson and Roberfroid, 1995). Prebiotics are substrates that are selectively utilised by host microorganisms, conferring a health benefit (Gibson et al., 2017). In early experiments it was observed that rats receiving prebiotics (eg. oligofructose, inulin) had a lower body fat mass but the mechanisms of action behind this were not understood. It was also noted that the 
rodents were consuming fewer calories (Cani et al., 2004) and that regardless of the disease model (eg. type 2 diabetes model or diet-induced obesity model), prebiotic treatment reduced glycaemia and improved insulin sensitivity (Cani et al., 2005a, 2006, 2007b, 2008; Everard et al., 2014). To understand these findings, researchers focused on the gut-brain interaction taking place while food is consumed. Different experiments have shown that the generation of different signals in the lower part of the gut can circulate and reach the brain. These signals include gut peptides [eg. glucagon-like peptide-1 (GLP-1) and peptide YY (PYY)] secreted by L-cells that have been seen to interact with specific receptors present in the portal vein and gut nerves (Chambers et al., 2015a).

In the brain, the integration of food derived-signals coming from the gut and from orexigenic (appetite-increasing) or anorexigenic (appetite-suppressing) neurons, is balanced. Such a process is key for controlling food intake and energy expenditure (Sohn, 2015). Interestingly, in the aforementioned rodent studies prebiotic intake was found to increase the production of GLP-1 and PYY and decrease the production of ghrelin. Furthermore, the studies showed that the expression of genes encoding proglucagon (a precursor of GLP-1) was increased in the lower part of the gut (Cani et al., 2004, 2005a, 2006, 2007b, 2008, 2009). This effect was reproduced in other experiments using different prebiotics (eg. resistant starch) and could possibly be explained by the activity of microbial metabolites generated from the fermentation of different prebiotic fibre types, including SCFA. These are found to bind to G-protein coupled receptors on the surface of L-cells (Cani et al., 2013), increasing satiety and decreasing food intake by triggering gut hormone secretion (Cani et al., 2004; Delzenne et al., 2005). In fact, in these studies increases in GLP-1 and GLP-2 were associated with an improvement in host phenotype (ie. decreased hunger, increased satiety, decreased fat mass and body weight and improved diabetes) (Cani et al., 2004, 2005a, 2005b, 2007a, 2007b; Kok et al., 1998). This association was confirmed when only a partial improvement of the phenotype was seen after prebiotic treatment in GLP-1 and GLP-2 receptor knockout mice (Cani et al., 2006, 2009; Delzenne et al., 2007). The mechanism behind this is unknown, but it is thought to be dependent on an increased number of L-cells in the colon, indeed recorded in rodents after prebiotic treatment (Cani et al., 2007a; Everard et al., 2011; Wichmann et al., 2013). The increase in the number of these cells may be associated with a higher differentiation of stem cells, which is hypothesised to be influenced by prebiotic consumption (Clevers and Batlle, 2013). Whilst theoretical at present, an understanding of how L-cell numbers can be increased could also aid the treatment of type 2 diabetes patients who currently receive GLP-1 injections as their endogenous production is low.

In addition to describing the impact of the fermentation of carbohydrates, Professor Cani also presented data suggesting that protein fermentation influences the balance of gut peptides. Protein fermentation can lead to indole production also suggested to be able to modulate the production of GLP-1 in that very high amounts can block GLP-1 secretion, whereas lower amounts, in combination with ions such as calcium, can stimulate GLP-1 secretion (Chimerel et al., 2014).

Other studies suggest that SCFA do not only act on the gut but can directly reach the brain and modulate the balance of signals to influence appetite. An elegant study showed that labelled acetate, infused intravenously and colonically, could cross the blood-brain-barrier in mice (Frost et al., 2014).

Professor Cani stressed that the impact of fibre and prebiotic consumption on host energy balance has not only been seen in rodents. Human studies also reported moderate reductions in body weight (2-2.5 kg) and visceral fat mass in overweight or obese subjects consuming 15-30 g daily of prebiotics such as inulin or resistant starch for 6-24 weeks. These studies also showed reduced hunger, increased satiety, increased PYY, decreased glycaemia and decreased plasma LPS (Chambers et al., 2015b; Daud et al., 2014; Dehghan et al., 2014; Dewulf et al., 2013; Gibson et al., 2017; Lecerf et al., 2012; Morel et al., 2015; Parnell and Reimer, 2009; Pourghassem Gargari et al., 2013).

Besides bacterial SCFAs and indole, neurotransmitters produced by bacteria also constitute a possible mechanism underlying prebiotic effects (Cani and Knauf, 2016). The endocannabinoid system influences a wide range of biological functions including food intake, adipose tissue browning and inflammation (Cani et al., 2014). Professor Cani's group has investigated whether specific gut bacteria can modulate the intestinal endocannabinoid system, focusing on the potential role of Akkermansia 
muciniphila in adipose tissue browning (via gut peptides and endocannabinoids) (Geurts et al., 2015; Muccioli et al., 2010). Studies of A. muciniphila treatment showed that this significantly increases the intestinal levels of two endocannabinoids found to be anti-inflammatory and one involved in the secretion of GLP-1 (Everard et al., 2013). Moreover, a strong correlation was found between A. muciniphila and L-cell numbers (Everard et al., 2011). Since this microbe is a propionate producer, it is also hypothesised to stimulate the production of GLP-1, GLP-2 and PYY.

In summary, various human and animal studies demonstrate that gut microbes have a considerable impact on host metabolism. This community can either act locally in the gut or can communicate with peripheral organs. Growing evidence suggest that metabolic products from the gut influence a myriad of metabolic pathways, contributing, among others, to the modulation of neurotransmitter production and hormonal balance (Rastelli et al., 2018).

\section{The role of microbiota in the prevention and treatment of cancer}

Professor Julian Marchesi (Imperial College London and Cardiff University, UK) pointed out that it is not enough to consider only the genome and the epigenome of an individual to understand noncommunicable diseases. Considering the microbiota is equally important given their functions and interactions with the host via metabolites (eg. SCFA, branched chain and decarboxylated amino acids, bile molecules) and proteins (Holmes et al., 2012). Our biology is so intertwined with microorganisms that our cells have receptors specifically for microbial metabolites. Furthermore, the composition of the gut microbiota can dictate how the host responds to drugs. Examples have shown that side effects related to a common colon cancer drug are caused by a gut bacterial enzyme (Wallace et al., 2010) and, conversely, that probiotics can interact with the immune system to promote the success of cancer treatments (Zitvogel et al., 2017).

The manifestation of several chronic diseases, including cancer, have an association with the microbiota found in the gut or other body sites (Nicholson et al., 2012). The gut microbiota can be the cause of an initial mutation as the result of an amensalistic relationship, defined as "an interaction in which one organism inflicts harm to another organism without receiving any costs or benefits" (Mougi, 2016). For example, colibactin, produced by certain strains of $E$. coli (a normal human commensal) and hydrogen sulphide produced by many gut bacteria, are both by-products of their normal bacterial metabolism, but at the same time are genotoxic molecules that can cause inflammation and trigger tumorigenesis. As these substances are part of their metabolism, they do not lend themselves to targeted preventative solutions for colorectal cancer (CRC) (Louis et al., 2014).

The vast variability in gut microbial composition clouds the issue of what constitutes a healthy versus an unhealthy microbiota. As such, the term "dysbiosis" may not be helpful as this also cannot be defined in concrete terms nor scientifically quantified (Olesen and Alm, 2016; Brüssow, 2020). Moreover, while a gut microbiota could be considered "normal" or "healthy" in one country, it could be different in another (De Filippo et al., 2010). Professor Marchesi suggests not to use the term "dysbiosis" indiscriminately, but only in those situations where bacteria appear in niches in which they are normally not found (eg. small intestinal organisms migrating to the large intestine after bariatric surgery).

In CRC, research seems to suggest that a specific "cancer microbiota" exists with specific communities living "on" or "off" the tumour. This work led to the development of the "driver/passenger hypothesis", which suggests that toxin-producing (but not pathogenic) bacteria can drive the development of CRC. Once a carcinoma has established, the bacterial community will change, normally becoming less diverse, although with the same bacterial load. Only certain bacteria can thrive in the tumour environment and these are thought of as "passengers" (Tjalsma et al., 2012). In particular, Fusobacterium is present in far higher quantities on advanced tumours (Castellarin et al., 2012; Kostic et al., 2012; Marchesi et al., 2011). Furthermore, in a study on bacterial abundance and co-occurrence, the bacteria present appear to change along with the disease stage from a benign cluster to a pathobiont cluster. Interestingly, as tumours become more invasive this seems to revert (Marchesi et al., 2011). The association of specific mutations driving the tumour with specific bacteria has also been analysed. Ascertaining which bacteria 
are typically present on tumours could be useful in developing more specific testing for CRC, as metabolites characteristically produced by these species could be measured.

In terms of CRC treatment, Professor Marchesi proposes a "TIMER mechanism" (standing for translocation, immunomodulation, metabolism, enzymatic degradation and reduced diversity) in that the microbiota modulates the responses to chemotherapy at different stages in the oncology pathway, something that can be externally exploited for the benefit of treatment (Alexander et al., 2017).

Professor Marchesi's group is interested in the proteome, particularly in proteases produced by gut bacteria, which are potential virulence factors in CRC and IBD (Steck et al., 2011). For example, in a cohort of $>500$ IBD patients, faecal protease activity was found to be high compared to healthy controls, likely to be metalloproteases driven by members of the Firmicutes (eg. clostridia, enterococci, lactobacilli). This correlated with high gut permeability and could be responsible for flare-ups in this patient group (Osborne and Marchesi, 2018).

In conclusion, newer ecologic concepts such as amensalism could help to guide us to a better understanding of the role of the microbiota in non-communicable diseases and the application of multimodal "omic" tools is required to determine the roles of the gut bacteria in cancer. Importantly, the microbiome needs to be considered in relation to cancer drug efficacy.

\section{Modelling the gut microbiota in vitro to assess food intervention efficacy and mode of action}

Professor Tom Van de Wiele (Ghent University, Belgium) focused further on the usefulness of in vitro models. He began his talk by highlighting the fact that there is high interindividual variability in studies measuring the possible health effects of food ingredients. This variation could be explained by numerous factors influencing the individual composition of the microbiota, such as the mode of delivery, being breast or formula fed, diet, lifestyle choices or antibiotic use (Bolca et al., 2013). Due to this complex interindividual variation, it may not be helpful to study the average response from a group of subjects when investigating the impact of a specific food component.

Thanks to initiatives such as the Human Microbiome Project Consortium (Human Microbiome Project Consortium, 2012), knowledge relating to the impact of microbes on health and disease has expanded. Researchers have moved from focusing on the phylogenetic compositional differences of the microbiota to exploring their metabolic potential and further relationship to the host. Based on these findings, molecular and physical interactions between the microbiota and the host seem to be more important for homeostasis than microbiota functionality, which is fairly stable between individuals. However, some health effects may actually depend on the unique metabolic potency of a specific microbial group or species. A good example of this is the conversion of daidzein, an isoflavone present in soy, to equol by gut bacteria present in only $33 \%$ of Caucasians. An equol producing phenotype has been found to have an impact on vasomotoric symptoms (such as hot flushes), osteoporosis (bone mineral density) and CVD risk markers (LDL cholesterol and C-reactive protein) (Jackson et al., 2011). Gut microbial composition therefore dictates whether an individual will gain health benefits from consuming soy isoflavones or not.

Understanding interindividual differences also requires consideration of the different microenvironments that exist within the individual gastrointestinal tract (GIT), eg. the proximal and the distal colon, as well as the luminal and mucosal regions, offering different nutrient platforms to the microbiota (Bäckhed et al., 2005). Studies limited to the analysis of stool samples only may not represent all of these microbial environments. For this reason, Professor van de Wiele has dedicated part of his work to optimising the Simulator of the Human Intestinal Microbial Ecosystem (SHIME) model to mimic the individual intestinal environment as closely as possible. SHIME is an in vitro system that includes the stomach, small intestine, proximal and distal colon (Marzorati and Van de Wiele, 2016) and includes mucosal platforms through the inclusion of microcosms that are coated with mucins to which bacteria can adhere. This allows researchers to focus on luminal microbes and those that adhere to the mucus platform (Marzorati et al., 2014; Van den Abbeele et al., 2013). SHIME suspensions can also be 
cocultured with host cells such as epithelial cells, hepatocytes and immune cells to study the interactions between the microbiota, the gut barrier and the immune system.

Two studies were presented in which SHIME was used to investigate hops and wheat bran as important ingredients to support host health. Hops contain bioactives such as isoxanthohumol (IX) which is being investigated as a potential cancer drug and thought to be the most potent plant hormone. IX can be converted to 8-prenylnaringin (8-PN) which is structurally quite similar to oestradiol and has therefore been proposed for the treatment or prevention of oestrogen-related pathologies such as breast cancer and menopausal symptoms. The conversion of IX to 8-PN has been noted to vary between female individuals, ranging from 0 to $100 \%$ (Possemiers et al., 2006). When faecal microbiota from high, medium and low 8-PN producers were added to the SHIME model, the conversion phenotype was found to be preserved (Molly et al., 1994; Possemiers et al., 2006) and revealed that conversion primarily took place in the distal colon. Furthermore, it was found that Eubacterium limosum, an IX converting microbe producing 8-PN, could improve the 8-PN producing phenotype in both in vitro and animal models.

Fibre is another important ingredient that can support human health. Modern diets tend to lack sufficient fibre. This may be detrimental, as fibre provides fuel for our microbiota (Scientific Advisory Committee on Nutrition, 2015). Wheat kernels contain several layers including the pericarp and the aleurone layers which differ as to how easily fermentable they are by the gut microbes. Interestingly, research suggests that wheat bran can drive microbiota niche diversification (De Paepe et al., 2017). Microscopy imaging of bran fractions incubated in the SHIME model showed that gut microbes can colonise these fractions. Compositional analyses showed that at the genus level, wheat bran colonising groups were highly variable among individuals but Clostridium cluster XIVa was enriched in all of them. Clostridium cluster XIVa are known butyrate producers often present in the mucosal environment which have important roles in maintaining barrier function and in stimulating regulatory $\mathrm{T}$ cells (Atarashi et al., 2011) and are found in lower abundance in IBD.

Accumulating research is focusing on the gut bacterium A. muciniphila (Derrien et al., 2017). In mice, high fat diets supplemented with A. muciniphila (alive, pasteurised or with a purified membrane protein isolated from the strain) resulted in lower body weight, lower levels of circulating LPS and lower insulin resistance, but with a stronger gut barrier function and an increased number of goblet cells, as compared to a normal diet (Plovier et al., 2017). In the human gut, abundance of A. muciniphila is highly variable (Derrien et al., 2008). In an attempt to understand in depth the driving factors for A. muciniphila to colonise the gut, the impact of mucin on intestinal colonisation was investigated using the SHIME model. In that study, the colonic environment of eight individuals was compared and the presence of mucin appeared to be the most important factor, not only modulating A. muciniphila colonisation, but also driving metabolic networks of the background microbiota. This primarily relates to mucin being a host glycan which can also be used as an energy source for the microbiota and thereby impacting host microbe interactions in general.

In conclusion, in vitro simulations of the GIT, such as the SHIME model, allow for the replication of the interindividual variability and functional signature of the microbiota from different individuals. This is important when investigating a food component which can have a different stimulatory effect on the compositional and metabolic networks of the gut microbial community.

\section{Mechanisms of probiotic activities: the needle in the haystack or too many to understand?}

Professor Sarah Lebeer (University of Antwerp, Belgium) started her presentation by pointing out that despite mechanistic studies on molecular interactions of probiotics being available in the literature, few examples exist where such molecular activities, measured by, eg. mutagenesis, microbiome sequencing or biomarker improvement, can adequately explain the targeted clinical effects or allow the prediction or selection of strains for particular clinical applications. 
Professor Lebeer agrees with describing probiotics as "bags of functions" and categorised these numerous functions or molecular mechanisms of action into the following (Lebeer et al., 2018): (i) modulation of the composition and activity of the indigenous microbiota, at least temporarily; (ii) enhancement of epithelial barrier function; (iii) modulation of the immune system; (iv) modulation of systemic metabolic responses and (v) signalling via the central nervous system.

Individual probiotic microorganisms have strain-specific properties, but different strains belonging to a taxonomic group may share core functions. For example, when considering lactic acid bacteria, a core property is that they all produce lactic acid; gram positive probiotic strains all have TLR2 ligands and bifidobacteria all contain mucus-binding proteins (Sanders et al., 2018). From a molecular perspective, behind the "bags of functions" are intracellular effector molecules in the form of enzymes (eg. lactase, bile salt hydrolases) and metabolites (lactate, SCFA, amino acids and derivatives), as well as effector molecules on the cell wall such as pili (Lebeer et al., 2018). The combination of core and specific mechanisms defines the final effect of a specific probiotic.

Lactobacillus rhamnosus GG (LGG) is arguably one of the most studied probiotics. It possesses several effectors against pathogens, including lactic acid (Makras et al., 2006; van den Broek et al., 2018) and lectin-like molecules (Petrova et al., 2016) that act in the gut and other niches like the upper respiratory tract. Bacteriocins, autoinducer-2 and peptide-based quorum sensing were also suspected to be involved, but this remains to be further substantiated (Lebeer et al., 2007). There is, however, increasing evidence that LGG can actively modulate the microbiota (Durack et al., 2018; Harata et al., 2017; Korpela et al., 2016). Exactly how this occurs has not been fully explained, but various ways in which LGG interacts with host epithelial cells and the important effector molecules have been documented. These include pili, extracellular polysaccharides, lipoteichoic acid, secreted proteins such as Msp1 and Msp2, and CpG DNA which is involved in TLR-9 interactions (Segers and Lebeer, 2014).

Comparative genomics is an interesting approach to find conserved (probiotic) features beyond LGG. Within the Lactobacillus casei group, three separate phylogenetic clades (groups of organisms with a common ancestor) exist, comprising the species L. paracasei, L. casei and L. rhamnosus respectively (Wuyts et al., 2017). It has long been known that LGG is more adherent than most lactobacilli and this is thought to be due to the specific type of pili on their surface (Tuomola et al., 1999). SpaCBA pili are made up of three subunits and promote adhesion to host cells through a "zipper-like" mechanism (Tripathi et al., 2013). The presence of SpaCBA pili is limited to the genomes of L. rhamnosus and L. paracasei (Douillard et al., 2013), while the L. casei group appears to harbour fimbriae composed of serine-rich glycoproteins (Wuyts et al., 2017). Another clade-specific property is resistance to oxidative stress, thought to be involved in the mechanism of action of probiotics, eg. against IBD (Tomusiak-Plebanek et al., 2018). All L. paracasei genomes have superoxidase dismutase, while L. casei genomes have catalase (Wuyts et al., 2017).

A better understanding of how probiotics work in the GIT can also be extended to the prediction of activities and functions in other niches (ie. ear, nose and throat; skin and vagina). Probiotics should be able to adapt to the local stress conditions and available nutrients in the specific niche(s) of interest. In addition, to promote health effects, they must show antipathogenic effects, epithelial barrier protection or immunomodulation (Lebeer et al., 2008). For example, LGG has been shown to be able to inhibit urogenital Candida infections by preventing the formation of hyphae, at least in part due to its exopolysaccharides (Wuyts et al., 2017) and this is now being studied in a clinical trial upon application in a specifically formulated topical gel. Present work is looking at the potential role of LGG in the prevention of upper respiratory tract infections (URTIs).

Professor Lebeer concluded that while looking for effector molecules of probiotics can seem like looking for a needle in a haystack and mechanistic work is slow and time consuming, it is worthwhile, especially because certain molecules have more of an effect than others and are therefore more important to focus on as they help to explain probiotic mechanisms of action. 


\section{Studies with Lactobacillus casei Shirota: what do they tell us?}

\section{Immunological effects of probiotics}

Dr Masanobu Nanno (Yakult Central Institute, Japan) explained the role of the gut microbiota in the development and maturation of the immune system during infancy. Perturbations of the microbiota early in life, if persistent rather than transient, can influence susceptibility to atopic, immune-mediated, metabolic and potentially neoplastic diseases in later life (Zeissig and Blumberg, 2014). Furthermore, gut bacterial composition and function can be altered at any life stage by various factors, including diet, severe mental stress, ageing, medication use and infection (Odamaki et al., 2016). These disturbances, termed dysbiosis, are associated with the occurrence of various diseases including diarrhoea, allergy, IBS, IBD or cancer, though cause and effect relationships have not always been established. In addition, the variation of gut microbial composition in diseased subjects is not uniform (Tsuji et al., 2018). In the future it may be possible to pinpoint exactly which compositional changes are critical in relation to disease (Nomoto and Matsuda, 2015).

Probiotics, defined as "live microorganisms that, when administered in adequate amounts, confer a health benefit on the host" (Hill et al., 2014; Joint FAO/WHO Working Group on Drafting Guidelines for the Evaluation of Probiotics in Food, 2007), may be promising agents for recovering from a disturbed microbiota or preventing the development of disease if consumed regularly as part of the diet. Safety, taxonomy and confirmation of health benefits are all important aspects of probiotic classification. The probiotic strain L. casei Shirota has been used by the food industry in Japan for more than 80 years. Dr Nanno presented data from several studies to support that $L$. casei Shirota survives the GIT, increases beneficial bacteria (lactobacilli and bifidobacteria) and SCFA in the gut and decreases harmful bacteria (such as Clostridium perfringens, Staphylococcus and Pseudomonas) and substances (such as p-cresol) (Bian et al., 2011; De Preter et al., 2004). Moreover, positive effects of L. casei Shirota have been shown on bowel habits and in reducing gut discomfort in the elderly (Koebnick et al., 2003; Sekita et al., 2015; Van den Nieuwboer et al., 2015). Findings were also shared from clinical studies showing the favourable effect of $L$. casei Shirota on infectious diarrhoea in children (Sur et al., 2011), antibiotic-associated diarrhoea (Pirker et al., 2013; Wong et al., 2014; Wright et al., 2015), upper respiratory tract infections (Fujita et al., 2013; Nagata et al., 2016; Van Puyenbroeck et al., 2012) and hypertension (Aoyagi et al., 2017).

One of the mechanisms by which probiotics exert their beneficial effects on humans is through modulation of the immune system. Researchers at the Yakult Central Institute are interested in how L. casei Shirota may have effects on the innate immune system measured by looking at natural killer (NK) cell activity. Low NK cell activity has been associated with a higher risk of cancer development (Imai et al., 2000) and L. casei Shirota consumption has been associated with a reduced incidence of superficial bladder and breast cancer in case-control studies (Aso et al., 1995; Toi et al., 2013), as well as a reduced reoccurrence of atypia of CRC cells in an intervention study (Ishikawa et al., 2005). Although the data looking at NK cell activity are not consistent, they point towards the existence of responders and non-responders (Dong et al., 2013; Nagao et al., 2000; Reale et al., 2012; Seifert et al., 2011; Shida et al., 2017; Spanhaak et al., 1998; Takeda et al., 2006). Dr Nanno speculated that $L$. casei Shirota has the potential to increase NK cell activity if it is consumed for a long enough period. In vitro studies have shown that interaction between activated monocytes and NK cells is important to enhance NK cell activity (Walzer et al., 2005) and experiments using human peripheral blood mononuclear cells indicate that $L$. casei Shirota triggers monocytes to produce IL-12 increasing the cytotoxicity of NK cells (Takeda et al., 2006). Furthermore, the cell wall polysaccharides of $L$. casei Shirota are thought to play a key role in the immune modulating activity, such as regulation of cytokine production (Yasuda et al., 2008). Type-1 polysaccharides (PS1) and type-2 polysaccharides (PS2) differ in that PS1 have a high molecular mass and a linear structure whereas the PS2 are smaller and have a branched structure (Nagaoka et al., 1990). When incubated with macrophages, mutants of $L$. casei Shirota that lack PS1 induced excessive production of proinflammatory cytokines compared to the wild-type probiotic, indicating that PS1 regulates the balance of cytokine production (Yasuda et al., 2008). Interestingly, in a colitis-associated cancer model in mice, the PS1-negative mutant strain did not modify the pathogenesis of dextran sulfate 
sodium-induced colon cancer, unlike the wild-type strain which prevented its development in association with the decreased production of the inflammatory cytokine IL-6 in the colonic mucosa (Matsumoto et al., 2009), further indicating that these polysaccharides are involved in the immune modulatory effect of L. casei Shirota. Additional data from in vitro work carried out using mouse peritoneal macrophages suggest that the cytokine production triggered by L. casei Shirota is not always consistent, as cytokine profiles appear to change depending on the presence or absence of teichoic acid derived from the cell wall of L. plantarum (Kaji et al., 2010). Dr Nanno ended his talk by hypothesising that, as L. casei Shirota can induce differing immune responses, depending on surrounding conditions (eg. presence or absence of inflammation), L. casei Shirota has the potential to have multiple effects, though more studies are required to fully understand how opposing effects can be exerted by the same strain and to define the right conditions for the application of the strain.

\section{Management of stress through the gut}

Professor Kensei Nishida (The University of Tokushima Graduate School, Japan) shared data from clinical trials conducted to explore whether probiotics, such as L. casei Shirota, can relieve the stressresponse in healthy medical students, related to taking an academic examination.

The existence of a bidirectional connection between the gut and the brain and its influence on our health has been known for a long time (Mayer, 2011). The gut-brain axis includes the central, the autonomic and the enteric nervous systems, as well as the hypothalamic-pituitary-adrenal (HPA) axis. Its function can be explained as hierarchically organised reflex loops, including the lowest reflex circuits contained within the enteric nervous system to the highest reflex loop involving areas of the brain that control emotional regulation (Mayer, 2011). Animal studies have indicated that the commensal microbiota can affect the development of the HPA stress response (Sudo et al., 2004) and it is now widely accepted that the enteric microbiota is part of this axis.

Stress, particularly chronic stress, is known to have a negative impact on wellbeing, including causing physical symptoms, such as abdominal dysfunction, as well as psychological symptoms, such as sleep disturbance and even depression. Professor Nishida and colleagues hypothesised that improvement of the gut environment using probiotics may have the potential to modulate the stress response and relieve stress-related symptoms. To investigate this, they pooled the results from three double-blind randomised, placebo-controlled trials that were conducted to examine the effects of $L$. casei Shirota on psychological and physiological stress responses in healthy medical students under academic examination stress (Takada et al., 2016). In these studies, the participants consumed either a fermented milk drink containing L. casei Shirota $\left(1.0 \times 10^{11}\right.$ colony forming units/day) or a placebo drink daily for 8 weeks until the day before the academic examination. Outcomes measured included laboratory parameters (salivary cortisol), physical symptoms (abdominal and cold symptoms), psychological parameters (current mental health, transitory emotional stress experienced before an event), as well as anxiety as a personality trait. In these pooled analyses, the $L$. casei Shirota intervention inhibited the appearance of stress-related physical symptoms and significantly suppressed salivary cortisol levels when compared to the placebo group. However, anxiety scores increased gradually, peaking the day before the examination and did not differ between the intervention groups. Gene expression profiles were assessed using DNA microarrays. Interestingly, L. casei Shirota administration almost completely prevented additional changes in the expression of stress-response genes one day before the examination (Kato-Kataoka et al., 2016). The composition of the gut microbiota was also measured using $16 \mathrm{~S}$ rRNA gene amplicon sequence analysis, and although there were no significant differences in the composition of phyla between the two groups at each time point, the proportion of Bacteroidetes tended to increase in the placebo group while it did not change in the probiotic group. L. casei Shirota administration was also able to preserve the phylogenetic diversity index (an indicator of alpha-diversity) before the examination, in contrast to placebo (Kato-Kataoka et al., 2016).

In a further double-blind, placebo-controlled trial following a similar protocol, Professor Nishida and colleagues aimed to evaluate whether probiotics could improve sleep quality or relieve stress-induced 
sleep disturbances in those students with an upcoming examination (Takada et al., 2017). In this trial, a total of 46 and 48 subjects consumed L. casei Shirota or placebo daily, 8 weeks prior to and 3 weeks after the examination. The absence of sleep disorders among the participants was ensured using the Pittsburgh Sleep Quality Index. Outcomes measured included subjective sleep quality, using the Oguri-ShirakaAzumi (OSA) sleep inventory which evaluates five factors (sleepiness on rising, initiation and maintenance of sleep, frequent dreaming, recovery from fatigue and sleep length), anxiety levels using the StateTrait Anxiety Index (STAI) and overnight electroencephalography (EEG) recordings. The STAI anxiety scores of both groups increased significantly 2 weeks before the exam and did not show difference between the treatment groups. The STAI score peak coincided with the lowest OSA score, indicating that stress affected sleep. Total OSA scores did not differ between the two groups across the study period, but compared to placebo, probiotic treatment was associated with significant positive effects on scores for "sleepiness on rising" and "sleep length" (no significant effects on other OSA parameters were found), and on "delta power" (an index of sleep intensity measured by EEG) as the exam approached. Moreover, L. casei Shirota was also associated with preventing EEG changes that were seen in the placebo group, in whom sleep latency lengthened and percentage of deep sleep (stage 3 non-REM) decreased as the examination approached. These data suggest that probiotics, such as $L$. casei Shirota, may have a beneficial effect on sleep quality during a stressful period.

Professor Nishida concluded his presentation by speculating that the mechanism behind $L$. casei Shirota acting on the brain to prevent the onset of stress-induced symptoms, may be through stimulation of the afferent vagus nerve that modulates the reactivity of both the HPA axis and the sympathetic nerve, therefore controlling the cortisol response initiated by stress (Takada et al., 2016), although these theories are yet to be further substantiated by human and mechanistic studies.

\section{A double-blind, placebo-controlled, randomised trial of probiotic therapy Lactobacillus casei Shirota in stable cirrhotic patients}

In liver cirrhosis, a pathological gut microbiota and bacterial translocation has been linked with immune dysfunction (Macnaughtan and Jalan, 2015). A pilot study of the probiotic strain L. casei Shirota in alcoholic cirrhosis demonstrated a significant improvement in neutrophil function (Stadlbauer et al., 2008).

Dr Jane Macnaughtan (University College London, UK) presented the results of a double blind, placebo-controlled study that aimed to evaluate the efficacy of $L$. casei Shirota with regard to improvement of immune function and effect on sepsis rates in patients with cirrhosis (Macnaughtan et al., 2017). In this study, 92 patients with cirrhosis of all causes and Child-Pugh score below 10, were randomised to receive $L$. casei Shirota or placebo, three times daily for six months. Randomisation was stratified by alcoholic and non-alcoholic aetiology ( $n=46$ per group). The researchers measured neutrophil function, plasma cytokines, endotoxin, serum bacterial DNA positivity, intestinal permeability and urine metabolomic profiles at day 0 , month 1 and month 6 .

The results showed that $L$. casei Shirota was associated with a significant improvement in neutrophil phorbol myristate acetate-induced ROS generation in patients with abnormal neutrophil function but not in the total population. L. casei Shirota also significantly reduced plasma monocyte chemotactic protein- 1 concentrations. In a subgroup analysis, $L$. casei Shirota significantly lowered plasma IL- $1 \beta$ in patients with alcoholic liver cirrhosis, whilst IL-17A and macrophage inflammatory protein-1 $\beta$ were significantly reduced in non-alcoholic cirrhotic patients compared with placebo. Clinical events (infection and decompensation) were low in both groups and this inevitably impacted on any potential efficacy signals from L. casei Shirota. No significant differences in intestinal permeability, markers of bacterial translocation or urinary metabolomic profile were observed between groups.

Dr Macnaughtan concluded that L. casei Shirota treatment in patients with early cirrhosis is safe and associated with an improvement in immune function that appears to occur independently of bacterial translocation and without any effect on the metabolomic profile. 


\section{Phage and probiotics: friends or foes?}

Professor Colin Hill (University College Cork, Ireland) started by reminding us that we live in a microbial world and that viruses massively outweigh bacteria in numbers.

Viruses that infect bacteria and Archaea are called bacteriophages (or phages) and most of them remain uncharacterised. Bacteria and phages are foes, although they coexist in three different scenarios. In a lytic infection, a phage attacks a bacterium and injects its nucleic acid that hijacks the cell, turning it into a phage-producing factory which then bursts to release new progeny. The multiplication factor can be as high as 1,000, a replication rate that can easily allow a bacterial culture to be overtaken. In a symbiotic relationship known as lysogeny, a phage integrates its genetic material into the bacterial genome in the form of a prophage which is copied each time the bacteria multiply. The prophage can induce the lytic cycle at any time. Finally, a bacterium can be phage-resistant through different mechanisms such as: blocking adsorption, preventing nuclear material entry, cleaving phage nucleic acid [eg. by restriction/modification or by the Clustered Regularly Interspaced Short Palindromic Repeats (CRISPR)-Cas system, discovered through study of a phage attack of $S$. thermophilus cultures (Barrangou et al., 2007)], impeding phage assembly or aborting phage infection systems.

Phages are found wherever bacteria live, including probiotics. Several potential interactions may occur when phages and probiotic bacteria meet. Phages can: (i) disrupt commercial probiotic production, (ii) kill probiotics entering the host, (iii) enter the lytic cycle in vivo, acting as markers for probiotic carriage; (iv) transfer genes to/from probiotic strains and (v) influence probiotic mechanisms of action.

Disruption of commercial probiotic production by phages is a persistent threat. Bacteriophages can cause extensive disruption to dairy fermentation due to their high virulence and their inhibitory effect on lactic acid formation. They can act against Lactococcus, Lactobacillus, Leuconostoc and Streptococcus species. Sophisticated methodologies have been developed in order to prevent phage infection during food production. For example, in cheese-making, closed systems are used along with phage-inhibiting media, rotation of starter cultures and direct inoculation. Yet, it has been discovered that phages appearing in "abnormal fermentations" had curiously occurred in closed tanks which should have been sterile. Indeed, these phages have been seen to come out of the probiotic strains themselves (ShimizuKadota et al., 1983). This points to, besides the implementation of closed systems, the possibility of using a strain resistant to specific phages. A successful example of this alternative was achieved by ShimizuKadota and colleagues who were able to develop a prophage-cured mutant which retained all the probiotic properties of a strain for making a fermented beverage (Shimizu-Kadota and Sakurai, 1982).

Bacterial genes may possess a CRISPR locus, representing a history of phage attack. A long history of exposure to phages has been demonstrated in B. longum as CRISPR loci are widespread (HidalgoCantabrana et al., 2017). A study employing electron micrographs to study pili of LGG (which has at least three prophage regions), noted that isometric bacteriophages could be observed in the background, possibly indicating that the phage components encoded by one of the genome islands are functional, and that phages can therefore emerge during culture (Kankainen et al., 2009). Phage resistant mechanisms can be stacked, rotated or mixed by food manufacturers to overcome phage attacks, though there may be regulatory issues if more than one version of the same bacteria is being used within probiotic production.

Phages have the potential to kill probiotics entering the host. In fact, phages against Lactobacillus paracase $i$ NFBC338 used to make a commercially available cheese, L. rhamnosus Lc 1/3 (related to LGG) and E. coli Nissle 1917 have been isolated from sewage and waste water (Alemayehu et al., 2009; Tuohimaa et al., 2006) indicating that phages against probiotics are present in the human body. Lysogenic phages can become lytic in vivo when facing a hostile environment, leading to the question of whether phages are present in the gut 'waiting' until individuals consume probiotics and whether this could explain observations of responders versus non-responders in clinical trials with probiotics. Furthermore, could constant consumption of one probiotic in high numbers select for an expansion of lytic phages? Investigating metagenomic databases for answers would be of interest.

Professor Hill also raised the question of whether phages can enter the lytic cycle in vivo and act as markers for probiotic carriage. Phages can be characterised within faeces using phageomics (viromics), a 
process consisting of physical separation of virus-like particles, DNA and RNA extraction and sequencing thereof by next generation sequencing methods and bioinformatic analysis (Shkoporov et al., 2018). Using this methodology to characterise samples from ten individuals, only a maximum of $0.5 \%$ of the phages found were known, indicating vast gaps in the current knowledge about them (Shkoporov et al., 2018). Phages are strain-specific, but for most of them the target is unknown. Nevertheless, such data suggest that they could be used as biomarkers for probiotic carriage. For example, phages differ between faecal samples from infants and elderly individuals in that more bifidobacterial phages (Bif $\Phi)$ and lactococcal phages are present in infants. Moreover, phageomics can distinguish 12 month old infants by delivery mode (vaginal vs. caesarean section) based on Bif $\Phi$ presence while bacterial $16 \mathrm{~S}$ rRNA analysis cannot discriminate between these groups (McCann et al., 2018). There is also evidence that phages play a role in the modulation of bacterial communities in the infant gut (Lugli et al., 2016).

He continued explaining that experiments in vitro have shown that phages can induce and facilitate gene transfer between bacteria, including probiotic strains. This could be used to human advantage by transferring genes with therapeutic interest, eg. chemokine genes for the expression of anti-HIV molecules (Damelin et al., 2010).

The interference of phages with probiotic mechanisms of action was illustrated by a study in which a prophage-cured derivative of $S$. thermophilus was found to be less effective when competing with pathogenic bacteria (Salmonella, Listeria and Staphylococcus aureus) for adhesion on HT29 epithelial cells as compared to a prophage-containing strain (Guigas et al., 2016), emphasising the importance of checking if probiotic traits remain in cured strains.

Professor Hill concluded that bacteria and phages are neither friends nor foes, but they are "in a relationship" and this needs to be considered when producing probiotics or performing studies with them. Phages can be useful in protecting against infectious bacteria and their ability to transfer plasmid genes to probiotics (Baugher et al., 2014).

Concluding remarks. The meeting was closed by Dr Bruno Pot (Yakult Europe, The Netherlands), whose concluding remarks highlighted the complexity of the probiotic-host relationship, therefore the difficulty of providing the scientific support needed for the substantiation of health claims for probiotics, and the fact that consumers are also now demanding, and are entitled to, information about the relationship between food products and health. Despite there being no health claims for probiotics accepted in Europe as yet, data presented at this meeting have demonstrated the many potential clinical applications for them.

\section{Notes on Contributors}

Stacey Lockyer has worked as a nutrition scientist at the British Nutrition Foundation since 2015, having completed her MSc and PhD at the University of Reading. Marisol Aguirre has published articles in the field of gut health focused on a compositional and functional microbiota signature from obese individuals, the morphology of a healthy intestine in broilers and in vitro gut modelling. She is a member of the Science Department of Yakult Europe. Louise Durrant is a Registered Dietitian and Science Manager at Yakult UK Ltd. After completing her dietetic degree at the University of Surrey (2011), she remained at the University to conduct a $\mathrm{PhD}$ in Nutritional Sciences focusing on the comparative efficacy of the two forms of vitamin D (2016) before joining Yakult UK shortly thereafter. Bruno Pot, $\mathrm{PhD}$ in microbiology from the University of Ghent, Belgium, has performed research in the area of lactic acid bacteria for close to 35 years. He is currently Science Director Europe at Yakult Europe (The Netherlands) and Guest Professor at the Vrije Universiteit Brussels (Belgium) and also involved in organisations as IPA, PRI, ILSI, LABIP, ISAPP. Kaori Suzuki MD, PhD has published several basic, translational, and clinical research articles on diverse biomedical areas. She works as Human Studies Manager at the Science Department of Yakult Europe. 
Disclosure statement. L.D. is employed by Yakult UK. M.A., K.S. and B.P. are employed by Yakult Europe. S.L. is employed by the British Nutrition Foundation. Yakult UK is a corporate member of the British Nutrition Foundation.

Funding. The speakers received an honorarium for their contribution and their travel costs were covered by Yakult Europe, B.V. S.L. received financial support (to cover travel and time) from Yakult Europe to attend the symposium and for time spent drafting this report.

Author contributions. S.L., M.A., L.D., and K.S. drafted the manuscript. S.L. and M.A. contributed equally to this work. B.P. reviewed the manuscript and provided critical feedback.

Publishing ethics statement. This manuscript is our own original work, and does not duplicate any other previously published work. This manuscript has been submitted only to this journal - it is not under consideration, accepted for publication or in press elsewhere. All listed authors know of and agree to the manuscript being submitted to the journal. This manuscript contains nothing that is abusive, defamatory, fraudulent, illegal, libellous or obscene.

Acknowledgements. All speakers approved a draft of their segment of the manuscript before submission.

\section{References}

Adachi Y, Moore LE, Bradford BU, Gao W and Thurman RG (1995) Antibiotics prevent liver injury in rats following longterm exposure to ethanol. Gastroenterology 108(1), 218-224.

Alemayehu D, Ross RP, O'Sullivan O, Coffey A, Stanton C, Fitzgerald GF and McAuliffe O (2009) Genome of a virulent bacteriophage Lb338-1 that lyses the probiotic Lactobacillus paracasei cheese strain. Gene 448(1), 29-39.

Alexander JL, Wilson ID, Teare J, Marchesi JR, Nicholson JK and Kinross JM (2017) Gut microbiota modulation of chemotherapy efficacy and toxicity. Nature Reviews Gastroenterology \& Hepatology 14(6), 356.

Aller R, De Luis D, Izaola O, Conde R, Gonzalez Sagrado M, Primo D, De La Fuente B and Gonzalez J (2011) Effect of a probiotic on liver aminotransferases in nonalcoholic fatty liver disease patients: A double blind randomized clinical trial. European Review for Medical and Pharmacological Sciences 15(9), 1090-1095.

Altamirano J and Bataller R (2011) Alcoholic liver disease: Pathogenesis and new targets for therapy. Nature Reviews Gastroenterology \& Hepatology 8, 491.

Antoni L, Nuding S, Wehkamp J and Stange EF (2014) Intestinal barrier in inflammatory bowel disease. World Journal of Gastroenterology 20(5), 1165-1179. https://doi.org/10.3748/wjg.v20.i5.1165

Aoyagi Y, Park S, Matsubara S, Honda Y, Amamoto R, Kushiro A, Miyazaki K and Shephard R (2017) Habitual intake of fermented milk products containing Lactobacillus casei strain Shirota and a reduced risk of hypertension in older people. Beneficial Microbes 8(1), 23-29.

Aso Y, Akaza H, Kotake T, Tsukamoto T, Imai K and Naito S (1995) Preventive effect of a Lactobacillus casei preparation on the recurrence of superficial bladder cancer in a double-blind trial. The BLP Study Group. European Urology 27, 104-109.

Atarashi K, Tanoue T, Shima T, Imaoka A, Kuwahara T, Momose Y, Cheng G, Yamasaki S, Saito T, Ohba Y, Taniguchi T, Takeda K, Hori S, Ivanov II, Umesaki Y, Itoh K and Honda K (2011) Induction of colonic regulatory T cells by indigenous Clostridium species. Science 331(6015), 337-341.

Bäckhed F, Ley RE, Sonnenburg JL, Peterson DA and Gordon JI (2005) Host-bacterial mutualism in the human intestine. Science 307(5717), 1915-1920.

Barker D, Hales C, Fall C, Osmond C, Phipps K and Clark P (1993) Type 2 (non-insulin-dependent) diabetes mellitus, hypertension and hyperlipidaemia (syndrome X): Relation to reduced fetal growth. Diabetologia 36, 62-67.

Barker D and Osmond C (1986) Infant mortality, childhood nutrition, and ischaemic heart disease in England and Wales. Lancet 327, 1077-1081.

Barrangou R, Fremaux C, Deveau H, Richards M, Boyaval P, Moineau S, Romero DA and Horvath P (2007) CRISPR provides acquired resistance against viruses in prokaryotes. Science 315(5819), 1709-1712.

Baugher J, Durmaz E and Klaenhammer T (2014) Spontaneously induced prophages in Lactobacillus gasseri contribute to horizontal gene transfer. Applied and Environmental Microbiology 80(11), 3508-3517.

Bergheim I, Weber S, Vos M, Krämer S, Volynets V, Kaserouni S, McClain CJ and Bischoff SC (2008) Antibiotics protect against fructose-induced hepatic lipid accumulation in mice: Role of endotoxin. Journal of Hepatology 48(6), 983-992.

Bernier-Latmani J, Cisarovsky C, Demir CS, Bruand M, Jaquet M, Davanture S, Ragusa S, Siegert S, Dormond O, Benedito R, Radtke F, Luther SA and Petrova TV (2015) DLL4 promotes continuous adult intestinal lacteal regeneration and dietary fat transport. Journal of Clinical Investigation 125(12), 4572-4586. https://doi.org/10.1172/JCI82045. 
Bian L, Nagata S, Asahara T, Rahman MS, Ohta T, Yuki N, Wang C, Takano K, Daibo M and Nomoto K (2011) Effects of the continuous intake of Lactobacillus casei strain Shirota-fermented milk on risk management of long-term inpatients at health facilities for the elderly. International Journal of Probiotics \& Prebiotics 6(2), 123-131.

Bolca S, Van de Wiele T and Possemiers S (2013) Gut metabotypes govern health effects of dietary polyphenols. Current Opinion in Biotechnology 24(2), 220-225.

Brïssow H (2020) Problems with the concept of gut microbiota dysbiosis. Microbial Biotechnology 13(2), 423-434.

Cani PD, Bibiloni R, Knauf C, Waget A, Neyrinck AM, Delzenne NM and Burcelin R (2008) Changes in gut microbiota control metabolic endotoxemia-induced inflammation in high-fat diet-induced obesity and diabetes in mice. Diabetes 57(6), 1470-1481.

Cani PD, Daubioul CA, Reusens B, Remacle C, Catillon G and Delzenne NM (2005a) Involvement of endogenous glucagonlike peptide-1(7-36) amide on glycaemia-lowering effect of oligofructose in streptozotocin-treated rats. Journal of Endocrinology 185(3), 457-465.

Cani PD, Dewever C and Delzenne NM (2004) Inulin-type fructans modulate gastrointestinal peptides involved in appetite regulation (glucagon-like peptide-1 and ghrelin) in rats. British Journal of Nutrition 92(3), 521-526.

Cani PD, Everard A and Duparc T (2013) Gut microbiota, enteroendocrine functions and metabolism. Current Opinion in Pharmacology 13(6), 935-940.

Cani PD, Geurts L, Matamoros S, Plovier H and Duparc T (2014) Glucose metabolism: Focus on gut microbiota, the endocannabinoid system and beyond. Diabetes \& Metabolism 40(4), 246-257.

Cani PD, Hoste S, Guiot Y and Delzenne NM (2007a) Dietary non-digestible carbohydrates promote L-cell differentiation in the proximal colon of rats. British Journal of Nutrition 98(1), 32-37.

Cani PD and Knauf C (2016) How gut microbes talk to organs: The role of endocrine and nervous routes. Molecular Metabolism 5(9), 743-752.

Cani PD, Knauf C, Iglesias MA, Drucker DJ, Delzenne NM and Burcelin R (2006) Improvement of glucose tolerance and hepatic insulin sensitivity by oligofructose requires a functional glucagon-like peptide 1 receptor. Diabetes 55(5), $1484-1490$.

Cani PD, Neyrinck AM, Fava F, Knauf C, Burcelin RG, Tuohy KM, Gibson G and Delzenne NM (2007b) Selective increases of bifidobacteria in gut microflora improve high-fat-diet-induced diabetes in mice through a mechanism associated with endotoxaemia. Diabetologia 50(11), 2374-2383.

Cani PD, Neyrinck AM, Maton N and Delzenne NM (2005b) Oligofructose promotes satiety in rats fed a high-fat diet: Involvement of glucagon-like peptide-1. Obesity Research 13(6), 1000-1007.

Cani PD, Possemiers S, Van de Wiele T, Guiot Y, Everard A, Rottier O, Geurts L, Naslain D, Neyrinck A, Lambert DM, Muccioli GG and Delzenne NM (2009) Changes in gut microbiota control inflammation in obese mice through a mechanism involving GLP-2-driven improvement of gut permeability. Gut 58(8), 1091-1103.

Castellarin M, Warren RL, Freeman JD, Dreolini L, Krzywinski M, Strauss J, Barnes R, Watson P, Allen-Vercoe E and Moore RA (2012) Fusobacterium nucleatum infection is prevalent in human colorectal carcinoma. Genome Research 22(2), 299-306.

Chambers ES, Morrison DJ and Frost G (2015a) Control of appetite and energy intake by SCFA: What are the potential underlying mechanisms? Proceedings of the Nutrition Society 74(03), 328-336.

Chambers ES, Viardot A, Psichas A, Morrison DJ, Murphy KG, Zac-Varghese SEK, MacDougall K, Preston T, Tedford C, Finlayson GS, Blundell JE, Bell JD, Thomas EL, Mt-Isa S, Ashby D, Gibson GR, Kolida S, Dhillo WS, Bloom SR, Morley W, Clegg S and Frost G (2015b) Effects of targeted delivery of propionate to the human colon on appetite regulation, body weight maintenance and adiposity in overweight adults. Gut 64(11), 1744-1754.

Chen L, Garmaeva S, Zhernakova A, Fu J and Wijmenga C (2018) A system biology perspective on environment-hostmicrobe interactions. Human Molecular Genetics 27, 1-8.

Chen Y, Yang F, Lu H, Wang B, Chen Y, Lei D, Wang Y, Zhu B and Li L (2011) Characterization of fecal microbial communities in patients with liver cirrhosis. Hepatology 54(2), 562-572.

Chimerel C, Emery E, Summers DK, Keyser U, Gribble FM and Reimann F (2014) Bacterial metabolite indole modulates incretin secretion from intestinal enteroendocrine L cells. Cell Reports 9(4), 1202-1208.

Cifarelli V and Eichmann A (2019) The Intestinal Lymphatic System: Functions and Metabolic Implications. Cellular and Molecular Gastroenterology and Hepatology 7(3), 503-513.

Clevers H and Batlle E (2013) SnapShot: The intestinal crypt. Cell 152(5), 1198-1198.

Damelin LH, Mavri-Damelin D, Klaenhammer TR and Tiemessen CT (2010) Plasmid transduction using bacteriophage Фadh for expression of CC chemokines by Lactobacillus gasseri ADH. Applied and Environmental Microbiology 76(12), 3878-3885.

Daud NM, Ismail NA, Thomas EL, Fitzpatrick JA, Bell JD, Swann JR, Costabile A, Childs CE, Pedersen C and Goldstone AP (2014) The impact of oligofructose on stimulation of gut hormones, appetite regulation and adiposity. Obesity 22(6), 14301438.

David LA, Maurice CF, Carmody RN, Gootenberg DB, Button JE, Wolfe BE, Ling AV, Devlin AS, Varma Y, Fischbach MA, Biddinger SB, Dutton RJ and Turnbaugh PJ (2013) Diet rapidly and reproducibly alters the human gut microbiome. Nature 505, 559. 
De Filippo C, Cavalieri D, Di Paola M, Ramazzotti M, Poullet JB, Massart S, Collini S, Pieraccini G and Lionetti P (2010) Impact of diet in shaping gut microbiota revealed by a comparative study in children from Europe and rural Africa. Proceedings of the National Academy of Sciences 107(33), 14691-14696.

De Paepe K, Kerckhof FM, Verspreet J, Courtin CM and Van de Wiele T (2017) Inter-individual differences determine the outcome of wheat bran colonization by the human gut microbiome. Environmental Microbiology 19(8), 3251-3267.

De Preter V, Geboes K, Verbrugghe K, De Vuyst L, Vanhoutte T, Huys G, Swings J, Pot B and Verbeke K (2004) The in vivo use of the stable isotope-labelled biomarkers lactose-[15 N] ureide and [2 H 4] tyrosine to assess the effects of pro-and prebiotics on the intestinal flora of healthy human volunteers. British Journal of Nutrition 92(3), 439-446.

Dehghan P, Gargari BP and Jafar-Abadi MA (2014d) Oligofructose-enriched inulin improves some inflammatory markers and metabolic endotoxemia in women with type 2 diabetes mellitus: A randomized controlled clinical trial. Nutrition 30(4), 418-423.

Del Chierico F, Valerio N, Pamela V, Alessandra R, De SC, Daniela G, Cesare F, Alessandro Z, Paola P, Giorgio C, Bruno D, Alfredo M, Anna A and Lorenza P (2017) Gut microbiota profiling of pediatric nonalcoholic fatty liver disease and obese patients unveiled by an integrated meta-omics-based approach. Hepatology 65(2), 451-464.

Delzenne N, Cani P, Daubioul C and Neyrinck A (2005) Impact of inulin and oligofructose on gastro-intestinal peptides. British Journal of Nutrition 93(S1), S157-S161.

Delzenne NM, Cani PD and Neyrinck AM (2007) Modulation of glucagon-like peptide 1 and energy metabolism by inulin and oligofructose: Experimental data. The Journal of Nutrition 137(11), 2547S-2551S.

Derrien M, Belzer C and de Vos WM (2017) Akkermansia muciniphila and its role in regulating host functions. Microbial Pathogenesis 106, 171-181.

Derrien M, Collado MC, Ben-Amor K, Salminen S and de Vos WM (2008) The mucin degrader Akkermansia muciniphila is an abundant resident of the human intestinal tract. Applied and Environmental Microbiology 74(5), 1646-1648.

Dewulf EM, Cani PD, Claus SP, Fuentes S, Puylaert PG, Neyrinck AM, Bindels LB, de Vos WM, Gibson GR, Thissen J-P and Delzenne NM (2013) Insight into the prebiotic concept: Lessons from an exploratory, double blind intervention study with inulin-type fructans in obese women. Gut 62(8), 1112-1121.

Dong H, Rowland I, Thomas LV and Yaqoob P (2013) Immunomodulatory effects of a probiotic drink containing Lactobacillus casei Shirota in healthy older volunteers. European Journal of Nutrition 52(8), 1853-1863. https://doi.org/ 10.1007/s00394-012-0487-1

Douillard FP, Ribbera A, Järvinen HM, Kant R, Pietilä TE, Randazzo C, Paulin L, Laine PK, Caggia C, von Ossowski I, Reunanen J, Satokari R, Salminen S, Palva A and de Vos WM (2013) Comparative genomic and functional analysis of Lactobacillus casei and Lactobacillus rhamnosus strains marketed as probiotics. Applied and Environmental Microbiology 79 (6), 1923-1933.

Durack J, Kimes NE, Lin DL, Rauch M, McKean M, McCauley K, Panzer AR, Mar JS, Cabana MD and Lynch SV (2018) Delayed gut microbiota development in high-risk for asthma infants is temporarily modifiable by Lactobacillus supplementation. Nature Communications 9(1), 707.

Everard A, Belzer C, Geurts L, Ouwerkerk JP, Druart C, Bindels LB, Guiot Y, Derrien M, Muccioli GG, Delzenne NM, de Vos WM and Cani PD (2013) Cross-talk between Akkermansia muciniphila and intestinal epithelium controls diet-induced obesity. Proceedings of the National Academy of Sciences 110(22), 9066-9071.

Everard A, Lazarevic V, Derrien M, Girard M, Muccioli GG, Neyrinck AM, Possemiers S, Van Holle A, François P, de Vos WM, Delzenne NM, Schrenzel J and Cani PD (2011) Responses of gut microbiota and glucose and lipid metabolism to prebiotics in genetic obese and diet-induced leptin-resistant mice. Diabetes 60(11), 2775-2786.

Everard A, Lazarevic V, Gaïa N, Johansson M, Ståhlman M, Backhed F, Delzenne NM, Schrenzel J, François P and Cani PD (2014) Microbiome of prebiotic-treated mice reveals novel targets involved in host response during obesity. The ISME Journal 8, 2116-2130.

Falony G, Joossens M, Vieira-Silva S, Wang J, Darzi Y, Faust K, Kurilshikov A Bonder MJ, Valles-Colomer M and Vandeputte D (2016) Population-level analysis of gut microbiome variation. Science 352(6285), 560-564.

Ferrere G, Wrzosek L, Cailleux F, Turpin W, Puchois V, Spatz M, Ciocan D, Rainteau D, Humbert L, Hugot C, Gaudin F, Noordine M-L, Robert V, Berrebi D, Thomas M, Naveau S, Perlemuter G and Cassard A-M (2017) Fecal microbiota manipulation prevents dysbiosis and alcohol-induced liver injury in mice. Journal of Hepatology 66(4), 806-815.

Frost G, Sleeth ML, Sahuri-Arisoylu M, Lizarbe B, Cerdan S, Brody L, Anastasovska J, Ghourab S, Hankir M and Zhang S (2014) The short-chain fatty acid acetate reduces appetite via a central homeostatic mechanism. Nature Communications 5, 3611 .

Fujita R, Iimuro S, Shinozaki T, Sakamaki K, Uemura Y, Takeuchi A, Matsuyama Y and Ohashi Y (2013) Decreased duration of acute upper respiratory tract infections with daily intake of fermented milk: A multicenter, double-blinded, randomized comparative study in users of day care facilities for the elderly population. American Journal of Infection Control 41(12), 1231-1235.

Geurts L, Everard A, Van Hul M, Essaghir A, Duparc T, Matamoros S, Plovier H, Castel J, Denis RG and Bergiers M (2015) Adipose tissue NAPE-PLD controls fat mass development by altering the browning process and gut microbiota. Nature Communications 6, 6495. 
Gibson GR, Hutkins R, Sanders ME, Prescott SL, Reimer RA, Salminen SJ, Scott K, Stanton C, Swanson KS and Cani PD (2017) Expert consensus document: The International Scientific Association for Probiotics and Prebiotics (ISAPP) consensus statement on the definition and scope of prebiotics. Nature Reviews Gastroenterology and Hepatology 14(8), 491.

Gibson GR and Roberfroid MB (1995) Dietary modulation of the human colonic microbiota: Introducing the concept of prebiotics. The Journal of Nutrition 125(6), 1401-1412.

Gopalakrishnan V, Spencer C, Nezi L, Reuben A, Andrews M, Karpinets T, Prieto P, Vicente D, Hoffman K and Wei S (2018) Gut microbiome modulates response to anti-PD-1 immunotherapy in melanoma patients. Science 359(6371), 97-103.

Greally JM (2018) A user's guide to the ambiguous word epigenetics. Nature Reviews Molecular Cell Biology 19, 207. https:// doi.org/10.1038/nrm.2017.135

Greenhalgh K, Meyer KM, Aagaard KM and Wilmes P (2016) The human gut microbiome in health: Establishment and resilience of microbiota over a lifetime. Environmental Microbiology 18(7), 2103-2116.

Guigas C, Faulhaber K, Duerbeck D, Neve H and Heller K (2016) Prophage-mediated modulation of interaction of Streptococcus thermophilus J34 with human intestinal epithelial cells and its competition against human pathogens. Beneficial Microbes 7(2), 289-297.

Gustot T, Lemmers A, Moreno C, Nagy N, Quertinmont E, Nicaise C, Franchimont D, Louis H, Devière J and Le Moine O (2006) Differential liver sensitization to toll-like receptor pathways in mice with alcoholic fatty liver. Hepatology 43(5), 989-1000.

Harata G, Kumar H, He F, Miyazawa K, Yoda K, Kawase M, Kubota A, Hiramatsu M, Rautava S and Salminen S (2017) Probiotics modulate gut microbiota and health status in Japanese cedar pollinosis patients during the pollen season. European Journal of Nutrition 56(7), 2245-2253.

Heintz-Buschart A, May P, Laczny CC, Lebrun LA, Bellora C, Krishna A, Wampach L, Schneider JG, Hogan A, de Beaufort $\mathbf{C}$ and Wilmes $\mathbf{P}$ (2016) Integrated multi-omics of the human gut microbiome in a case study of familial type 1 diabetes. Nature Microbiology 2, 16180.

Heintz-Buschart A and Wilmes P (2018) Human gut microbiome: Function matters. Trends in Microbiology 26(7), 563-574.

Hidalgo-Cantabrana C, Crawley AB, Sanchez B and Barrangou R (2017) Characterization and exploitation of CRISPR loci in Bifidobacterium longum. Frontiers in Microbiology 8, 1851.

Hill C, Guarner F, Reid G, Gibson GR, Merenstein DJ, Pot B, Morelli L, Canani RB, Flint HJ and Salminen S (2014) Expert consensus document: The International Scientific Association for Probiotics and Prebiotics consensus statement on the scope and appropriate use of the term probiotic. Nature Reviews Gastroenterology and Hepatology 11(8), 506.

Holmes E, Li JV, Marchesi JR and Nicholson JK (2012) Gut microbiota composition and activity in relation to host metabolic phenotype and disease risk. Cell Metabolism 16(5), 559-564.

Hooper LV and Macpherson AJ (2010) Immune adaptations that maintain homeostasis with the intestinal microbiota. Nature Reviews Immunology 10(3), 159.

Human Microbiome Project Consortium (2012) Structure function and diversity of the healthy human microbiome. Nature 486(7402), 207-214.

Imai K, Matsuyama S, Miyake S, Suga K and Nakachi K (2000) Natural cytotoxic activity of peripheral-blood lymphocytes and cancer incidence: An 11-year follow-up study of a general population. The Lancet 356(9244), 1795-1799.

Imhann F, Bonder M, Fu J, Mujagic Z, Vork L, Tigchelaar E, Jankipersadsing S, Cenit M, Harmsen H and Dijkstra G (2016) Proton pump inhibitors affect the gut microbiome. Gut 65(5), 740-748.

Imhann F, Vich Vila A, Bonder MJ, Lopez Manosalva AG, Koonen DPY, Fu J, Wijmenga C, Zhernakova A and Weersma RK (2017) The influence of proton pump inhibitors and other commonly used medication on the gut microbiota. Gut Microbes 8(4), 351-358.

Ishikawa H, Akedo I, Otani T, Suzuki T, Nakamura T, Takeyama I, Ishiguro S, Miyaoka E, Sobue T and Kakizoe T (2005) Randomized trial of dietary fiber and Lactobacillus casei administration for prevention of colorectal tumors. International Journal of Cancer 116(5), 762-767.

Jackson RL, Greiwe JS and Schwen RJ (2011) Emerging evidence of the health benefits of S-equol, an estrogen receptor $\beta$ agonist. Nutrition Reviews 69(8), 432-448.

Jiménez-Chillarón JC, Díaz R, Martínez D, Pentinat T, Ramón-Krauel M, Ribó S and Plösch T (2012) The role of nutrition on epigenetic modifications and their implications on health. Biochimie 94(11), 2242-2263.

Joint FAO/WHO Working Group on Drafting Guidelines for the Evaluation of Probiotics in Food (2007) Guidelines for the evaluation of probiotics in food: Report of a Joint FAO/WHO Working Group London Ontario Canada April 30 and May 1, 2002. Available at http://www.who.int/foodsafety/fs_management/en/probiotic_guidelines.pdf (accessed 13 August 2018).

Kaji R, Kiyoshima-Shibata J, Nagaoka M, Nanno M and Shida K (2010) Bacterial teichoic acids reverse predominant IL-12 production induced by certain Lactobacillus strains into predominant IL-10 production via TLR2-dependent ERK activation in macrophages. The Journal of Immunology 184(7), 3505-3513. 
Kankainen M, Paulin L, Tynkkynen S, von Ossowski I, Reunanen J, Partanen P, Satokari R, Vesterlund S, Hendrickx AP and Lebeer S (2009) Comparative genomic analysis of Lactobacillus rhamnosus GG reveals pili containing a human-mucus binding protein. Proceedings of the National Academy of Sciences 106(40), 17193-17198.

Kanuri G, Ladurner R, Skibovskaya J, Spruss A, Königsrainer A, Bischoff SC and Bergheim I (2015) Expression of toll-like receptors $1-5$ but not TLR $6-10$ is elevated in livers of patients with non-alcoholic fatty liver disease. Liver International 35 (2), 562-568.

Kato-Kataoka A, Nishida K, Takada M, Kawai M, Kikuchi-Hayakawa H, Suda K, Ishikawa H, Gondo Y, Shimizu K and Matsuki T (2016) Fermented milk containing Lactobacillus casei strain Shirota preserves the diversity of the gut microbiota and relieves abdominal dysfunction in healthy medical students exposed to academic stress. Applied and Environmental Microbiology 82(12), 3649-3658.

Kitano H (2001) Systems biology: Toward system-level understanding of biological systems. Foundations of Systems Biology. Cambridge, MA: The MIT Press, pp. 1-36.

Koebnick C, Wagner I, Leitzmann P, Stern U and Zunft H (2003) Probiotic beverage containing Lactobacillus casei Shirota improves gastrointestinal symptoms in patients with chronic constipation. Canadian Journal of Gastroenterology and Hepatology 17(11), 655-659.

Koeninger L, Armbruster NS, Hu Z, Jensen B, Stange EF, Nordkild P, Malek NP, Zender L and Wehkamp J (2018) P851 oral delivery of human $\beta$-defensin 2 is reversibly increasing microbiome diversity and is effective in the treatment of experimental colitis. Journal of Crohn's and Colitis 12(supplement_1), S547.

Kok NN, Morgan LM, Williams CM, Roberfroid MB, Thissen J-P and Delzenne NM (1998) Insulin glucagon-like peptide 1, glucose-dependent insulinotropic polypeptide and insulin-like growth factor 1 as putative mediators of the hypolipidemic effect of oligofructose in rats. The Journal of Nutrition 128(7), 1099-1103.

Korpela K, Salonen A, Virta LJ, Kumpu M, Kekkonen RA and De Vos WM (2016) Lactobacillus rhamnosus GG intake modifies preschool children's intestinal microbiota, alleviates penicillin-associated changes, and reduces antibiotic use. PloS One 11(4), e0154012.

Kostic AD, Gevers D, Pedamallu CS, Michaud M, Duke F, Earl AM, Ojesina AI, Jung J, Bass AJ and Tabernero J (2012) Genomic analysis identifies association of Fusobacterium with colorectal carcinoma. Genome Research 22(2), 292-298.

Le Chatelier E, Nielsen T, Qin J, Prifti E, Hildebrand F, Falony G, Almeida M, Arumugam M, Batto J-M and Kennedy S (2013) Richness of human gut microbiome correlates with metabolic markers. Nature 500(7464), 541-546.

Lebeer S, Bron PA, Marco ML, Van Pijkeren J-P, Motherway MOC, Hill C, Pot B, Roos S and Klaenhammer T (2018) Identification of probiotic effector molecules: Present state and future perspectives. Current Opinion in Biotechnology 49, 217-223.

Lebeer S, De Keersmaecker SC, Verhoeven TL, Fadda AA, Marchal K and Vanderleyden J (2007) Functional analysis of luxS in the probiotic strain Lactobacillus rhamnosus GG reveals a central metabolic role important for growth and biofilm formation. Journal of Bacteriology 189(3), 860-871.

Lebeer S, Vanderleyden J and De Keersmaecker SC (2008) Genes and molecules of lactobacilli supporting probiotic action. Microbiology and Molecular Biology Reviews 72(4), 728-764.

Lecerf J-M, Dépeint F, Clerc E, Dugenet Y, Niamba CN, Rhazi L, Cayzeele A, Abdelnour G, Jaruga A, Younes H, Jacobs H, Lambrey G, Abdelnour AM and Pouillart PR (2012) Xylo-oligosaccharide (XOS) in combination with inulin modulates both the intestinal environment and immune status in healthy subjects, while XOS alone only shows prebiotic properties. British Journal of Nutrition 108(10), 1847-1858.

Lehrer RI (2011) Peptide gets in shape for self-defence. Nature 469, 309.

Llopis M, Cassard AM, Wrzosek L, Boschat L, Bruneau A, Ferrere G, Puchois V, Martin JC, Lepage P, Le Roy T, Lefevre L, Langelier B, Cailleux F, Gonzalez-Castro AM, Rabot S, Gaudin F, Agostini H, Prevot S, Berrebi D, Ciocan D, Jousse C, Naveau S, Gerard P and Perlemuter G (2016) Intestinal microbiota contributes to individual susceptibility to alcoholic liver disease. Gut 65(5), 830-839.

Louis P, Hold GL and Flint HJ (2014) The gut microbiota, bacterial metabolites and colorectal cancer. Nature Reviews Microbiology 12(10), 661.

Lugli GA, Milani C, Turroni F, Tremblay D, Ferrario C, Mancabelli L, Duranti S, Ward DV, Ossiprandi MC and Moineau S (2016) Prophages of the genus Bifidobacterium as modulating agents of the infant gut microbiota. Environmental Microbiology 18(7), 2196-2213.

Macnaughtan J and Jalan R (2015) Clinical and pathophysiological consequences of alterations in the microbiome in cirrhosis. The American Journal of Gastroenterology 110(10), 1399-1410.

Macnaughtan J, Figorilli F, García-López E, Lu H, JonesH, Sawhney R, Suzuki K, Fairclough S, Marsden J. Moratella A, Cox IJ, Thomas L, Davies N, Williams R, Mookerjee R, Wright G, Jalan RA (2020) A Double-Blind, Randomized PlaceboControlled Trial of Probiotic Lactobacillus casei Shirota in Stable Cirrhotic Patients. Nutrients 12(6) E1651.

Makras L, Triantafyllou V, Fayol-Messaoudi D, Adriany T, Zoumpopoulou G, Tsakalidou E, Servin A and De Vuyst L (2006) Kinetic analysis of the antibacterial activity of probiotic lactobacilli towards Salmonella enterica serovar Typhimurium reveals a role for lactic acid and other inhibitory compounds. Research in Microbiology 157(3), 241-247. 
Marchesi JR, Dutilh BE, Hall N, Peters WH, Roelofs R, Boleij A and Tjalsma H (2011) Towards the human colorectal cancer microbiome. PLoS One 6(5), e20447.

Martínez D, Pentinat T, Ribó S, Daviaud C, Bloks VW, Cebrià J, Villalmanzo N, Kalko SG, Ramón-Krauel M and Díaz R (2014) In utero undernutrition in male mice programs liver lipid metabolism in the second-generation offspring involving altered Lxra DNA methylation. Cell Metabolism 19(6), 941-951.

Marzorati M and Van de Wiele T (2016) An advanced in vitro technology platform to study the mechanism of action of prebiotics and probiotics in the gastrointestinal tract. Journal of Clinical Gastroenterology 50, S124-S125.

Marzorati M, Vanhoecke B, De Ryck T, Sadabad MS, Pinheiro I, Possemiers S, Van den Abbeele P, Derycke L, Bracke M and Pieters J (2014) The HMI ${ }^{\mathrm{Tm}}$ module: A new tool to study the Host-Microbiota Interaction in the human gastrointestinal tract in vitro. BMC Microbiology 14(1), 133.

Matsumoto S, Hara T, Nagaoka M, Mike A, Mitsuyama K, Sako T, Yamamoto M, Kado S and Takada T (2009) A component of polysaccharide peptidoglycan complex on Lactobacillus induced an improvement of murine model of inflammatory bowel disease and colitis-associated cancer. Immunology 128(1pt2), e170-e180.

Mayer EA (2011) Gut feelings: The emerging biology of gut-brain communication. Nature Reviews Neuroscience 12(8), 453-466.

McCann A, Ryan FJ, Stockdale SR, Dalmasso M, Blake T, Ryan CA, Stanton C Mills S, Ross PR and Hill C (2018) Viromes of one year old infants reveal the impact of birth mode on microbiome diversity. PeerJ 6, e4694.

Miele L, Valenza V, La Torre G, Montalto M, Cammarota G, Ricci R, Masciana R, Forgione A, Gabrieli ML and Perotti G (2009) Increased intestinal permeability and tight junction alterations in nonalcoholic fatty liver disease. Hepatology 49(6), 1877-1887.

Mischke M and Plösch T (2013) More than just a gut instinct-the potential interplay between a baby's nutrition, its gut microbiome, and the epigenome. American Journal of Physiology-Regulatory Integrative and Comparative Physiology 304(12), R1065-R1069.

Mischke M and Plösch T (2016) The gut microbiota and their metabolites: Potential implications for the host epigenome Microbiota of the Human Body. Berlin, Germany: Springer, pp. 33-44.

Molina PE, Gardner JD, Souza-Smith FM and Whitaker AM (2014) Alcohol abuse: Critical pathophysiological processes and contribution to disease burden. Physiology 29(3), 203-215.

Molly K, Woestyne MV, Smet ID and Verstraete W (1994) Validation of the Simulator of the Human Intestinal Microbial Ecosystem (SHIME) reactor using microorganism-associated activities. Microbial Ecology in Health and Disease 7(4), 191-200.

Mondel M, Schroeder BO, Zimmermann K, Huber H, Nuding S, Beisner J, Fellermann K, Stange EF and Wehkamp J (2009) Probiotic E. coli treatment mediates antimicrobial human beta-defensin synthesis and fecal excretion in humans. Mucosal Immunology 2(2), 166-172.

Morel FB, Dai Q, Ni J, Thomas D, Parnet P and Fança-Berthon P (2015) $\alpha$-Galacto-oligosaccharides dose-dependently reduce appetite and decrease inflammation in overweight adults. The Journal of Nutrition 145(9), 2052-2059.

Mougi A (2016) The roles of amensalistic and commensalistic interactions in large ecological network stability. Scientific Reports 6, 29929.

Muccioli GG, Naslain D, Bäckhed F, Reigstad CS, Lambert DM, Delzenne NM and Cani PD (2010) The endocannabinoid system links gut microbiota to adipogenesis. Molecular Systems Biology 6(1), 392.

Muller EE, Pinel N, Laczny CC, Hoopmann MR, Narayanasamy S, Lebrun LA, Roume H, Lin J, May P, Hicks ND, HeintzBuschart A, Wampach L, Liu CM, Price LB, Gillece JD, Guignard C, Schupp JM, Vlassis N, Baliga NS, Moritz RL, Keim PS and Wilmes P (2014) Community-integrated omics links dominance of a microbial generalist to fine-tuned resource usage. Nature Communications 5, 5603.

Muller EEL, Glaab E, May P, Vlassis N and Wilmes P (2013) Condensing the omics fog of microbial communities. Trends in Microbiology 21(7), 325-333.

Mutlu EA, Gillevet PM, Rangwala H, Sikaroodi M, Naqvi A, Engen PA, Kwasny M Lau CK and Keshavarzian A (2012) Colonic microbiome is altered in alcoholism. American Journal of Physiology-Heart and Circulatory Physiology 302(9), G966-G978.

Nabavi S, Rafraf M, Somi M, Homayouni-Rad A and Asghari-Jafarabadi M (2014) Effects of probiotic yogurt consumption on metabolic factors in individuals with nonalcoholic fatty liver disease. Journal of Dairy Science 97(12), 7386-7393.

Nagao F, Nakayama M, Muto T and Okumura K (2000) Effects of a fermented milk drink containing Lactobacillus casei strain Shirota on the Immune System in Healthy Human Subjects. Bioscience Biotechnology and Biochemistry 64(12), $2706-2708$.

Nagaoka M, Muto M, Nomoto K, Matuzaki T, Watanabe T and Yokokura T (1990) Structure of polysaccharide-peptidoglycan complex from the cell wall of Lactobacillus casei YIT9018. The Journal of Biochemistry 108(4), 568-571.

Nagata S, Asahara T, Wang C, Suyama Y, Chonan O, Takano K, Daibou M, Takahashi T, Nomoto K and Yamashiro Y (2016) The effectiveness of Lactobacillus beverages in controlling infections among the residents of an aged care facility: A randomized placebo-controlled double-blind trial. Annals of Nutrition and Metabolism 68(1), 51-59.

Netherlands Organ-on-Chip Initiative Major grant for 'Organ-on-a-chip' research. Available at https://noci-organ-onchip.nl/major-grant-for-organ-on-a-chip-research/ (accessed 1 July 2018) 
Nicholson JK, Holmes E, Kinross J, Burcelin R, Gibson G, Jia W and Pettersson S (2012) Host-gut microbiota metabolic interactions. Science 336(6086), 1262-1267.

Nier A, Engstler AJ, Maier IB and Bergheim I (2017) Markers of intestinal permeability are already altered in early stages of non-alcoholic fatty liver disease: Studies in children. PLoS One 12(9), e0183282.

Nomoto LTH and Matsuda K (2015) YIF-SCAN: A novel system for intestinal microbiota analysis. Journal of Intestinal Microbiology 29(1), 9-18.

Odamaki T, Kato K, Sugahara H, Hashikura N, Takahashi S, Xiao J-Z, Abe F and Osawa R (2016) Age-related changes in gut microbiota composition from newborn to centenarian: A cross-sectional study. BMC Microbiology 16(1), 90.

Olesen SW and Alm EJ (2016) Dysbiosis is not an answer. Nature Microbiology 1, 16228.

Osborne LS and Marchesi J (2018) P859 The functional exoproteome as a driver and predictor of IBD status: Proteases from bacteria influence host health. Journal of Crohn's and Colitis 12(supplement_1), S551.

Painter R, Roseboom T and Bleker O (2005) Prenatal exposure to the Dutch famine and disease in later life: An overview. Reproductive Toxicology 20(3), 345-352.

Parks BW, Nam E, Org E, Kostem E, Norheim F, Hui ST, Pan C, Civelek M, Rau CD and Bennett BJ (2013) Genetic control of obesity and gut microbiota composition in response to high-fat, high-sucrose diet in mice. Cell Metabolism 17(1), 141-152.

Parlesak A, Schäfer C, Schütz T, Bode JC and Bode C (2000) Increased intestinal permeability to macromolecules and endotoxemia in patients with chronic alcohol abuse in different stages of alcohol-induced liver disease. Journal of Hepatology 32(5), 742-747.

Parnell JA and Reimer RA (2009) Weight loss during oligofructose supplementation is associated with decreased ghrelin and increased peptide YY in overweight and obese adults. The American Journal of Clinical Nutrition 89(6), 1751-1759.

Pelczar P, Witkowski M, Perez LG, Kempski J, Hammel AG, Brockmann L, Kleinschmidt D, Wende S, Haueis C, Bedke T, Witkowski M, Krasemann S, Steurer S, Booth CJ, Busch P, König A, Rauch U, Benten D, Izbicki JR, Rösch T, Lohse AW, Strowig T, Gagliani N, Flavell RA and Huber S (2016) A pathogenic role for T cell-derived IL-22BP in inflammatory bowel disease. Science 354(6310), 358-362.

Petrova MI, Imholz NC, Verhoeven TL, Balzarini J, Van Damme EJ, Schols D, Vanderleyden J and Lebeer S (2016) Lectinlike molecules of Lactobacillus rhamnosus GG inhibit pathogenic Escherichia coli and Salmonella biofilm formation. PLoS One 11(8), e0161337.

Pirker A, Stockenhuber A, Remely M, Harrant A, Hippe B, Kamhuber C, Adelmann K, Stockenhuber F and Haslberger AG (2013) Effects of antibiotic therapy on the gastrointestinal microbiota and the influence of Lactobacillus casei. Food and Agricultural Immunology 24(3), 315-330.

Plovier H, Everard A, Druart C, Depommier C, Van Hul M, Geurts L, Chilloux J, Ottman N, Duparc T, Lichtenstein L, Myridakis A, Delzenne NM, Klievink J, Bhattacharjee A, van der Ark KC, Aalvink S, Martinez LO, Dumas ME, Maiter D, Loumaye A, Hermans MP, Thissen JP, Belzer C, de Vos WM and Cani PD (2017) A purified membrane protein from Akkermansia muciniphila or the pasteurized bacterium improves metabolism in obese and diabetic mice. Nature Medicine 23(1), 107-113.

Possemiers S, Bolca S, Grootaert C, Heyerick A, Decroos K, Dhooge W, De Keukeleire D, Rabot S, Verstraete W and Van de Wiele T (2006) The prenylflavonoid isoxanthohumol from hops (Humulus lupulus L.)is activated into the potent phytoestrogen 8-prenylnaringenin in vitro and in the human intestine. The Journal of Nutrition 136(7), $1862-1867$.

Pourghassem Gargari B, Dehghan P, Aliasgharzadeh A and Asghari Jafar-abadi, M (2013) Effects of high performance inulin supplementation on glycemic control and antioxidant status in women with type 2 diabetes. Diabetes \& Metabolism Journal 37(2), 140-148.

Purohit V, Bode JC, Bode C, Brenner DA, Choudhry MA, Hamilton F, Kang YJ, Keshavarzian A, Rao R, Sartor RB, Swanson C and Turner JR (2008) Alcohol intestinal bacterial growth, intestinal permeability to endotoxin, and medical consequences: Summary of a symposium. Alcohol 42(5), 349-361.

Quigley EMM (2010) Prebiotics and probiotics; modifying and mining the microbiota. Pharmacological Research 61(3), 213-218.

Raschig J, Mailänder-Sánchez D, Berscheid A, Berger J, Strömstedt AA, Courth LF, Malek NP, Brötz-Oesterhelt H and Wehkamp J (2017) Ubiquitously expressed Human Beta Defensin 1 (hBD1) forms bacteria-entrapping nets in a redox dependent mode of action. PLOS Pathogens 13(3), e1006261.

Rastelli M, Knauf C and Cani PD (2018) Gut microbes and health: A focus on the mechanisms linking microbes obesity and related disorders. Obesity 26(5), 792-800.

Reale M, Boscolo P, Bellante V, Tarantelli C, Di Nicola M, Forcella L, Li Q, Morimoto K and Muraro R (2012) Daily intake of Lactobacillus casei Shirota increases natural killer cell activity in smokers. British Journal of Nutrition 108(2), 308-314.

Rescigno M (2017) The microbiota revolution: Excitement and caution. European Journal of Immunology 47(9), 1406-1413.

Ridaura VK, Faith JJ, Rey FE, Cheng J, Duncan AE, Kau AL, Griffin NW, Lombard V, Henrissat B and Bain JR (2013) Gut microbiota from twins discordant for obesity modulate metabolism in mice. Science 341(6150), 1241214.

Rivera CA, Bradford BU, Seabra V and Thurman RG (1998) Role of endotoxin in the hypermetabolic state after acute ethanol exposure. American Journal of Physiology-Gastrointestinal and Liver Physiology 275(6), G1252-G1258. 
Roume H, El Muller E, Cordes T, Renaut J, Hiller K and Wilmes P (2012) A biomolecular isolation framework for eco-systems biology. The ISME Journal 7, 110-121.

Roume H, Heintz-Buschart A, Muller EEL, May P, Satagopam VP, Laczny CC, Narayanasamy S, Lebrun LA, Hoopmann MR, Schupp JM, Gillece JD, Hicks ND, Engelthaler DM, Sauter T, Keim PS, Moritz RL and Wilmes P (2015) Comparative integrated omics: Identification of key functionalities in microbial community-wide metabolic networks. NPJ Biofilms and Microbiomes 1, 15007.

Roume H, Heinz-Buschart A, Muller E and Wilmes P (2013) Sequencial isolation of metabolites, RNA, DNA and proteins from the same unique sample. In DeLong EF (ed.), Microbial Metagenomics Metatranscriptomics and Metaproteomics. Vol. 531. San Diego, CA: Academic Press Elsevier, pp. 688.

Routy B, Le Chatelier E, Derosa L, Duong CPM, Alou MT, Daillère R, Fluckiger A, Messaoudene M, Rauber C, Roberti MP, Fidelle M, Flament C, Poirier-Colame V, Opolon P, Klein C, Iribarren K, Mondragón L, Jacquelot N, Qu B, Ferrere G, Clémenson C, Mezquita L, Masip JR, Naltet C, Brosseau S, Kaderbhai C, Richard C, Rizvi H, Levenez F, Galleron N, Quinquis B, Pons N, Ryffel B, Minard-Colin V, Gonin P, Soria J-C, Deutsch E, Loriot Y, Ghiringhelli F, Zalcman G, Goldwasser F, Escudier B, Hellmann MD, Eggermont A, Raoult D, Albiges L, Kroemer G and Zitvogel L (2018) Gut microbiome influences efficacy of PD-1-based immunotherapy against epithelial tumors. Science 359(6371), 91-97.

Sáez-Lara M, Robles-Sanchez C, Ruiz-Ojeda F, Plaza-Diaz J and Gil A (2016) Effects of probiotics and synbiotics on obesity, insulin resistance syndrome, type 2 diabetes and non-alcoholic fatty liver disease: A review of human clinical trials. International Journal of Molecular Sciences 17(6), 928.

Salzman NH, Hung K, Haribhai D, Chu H, Karlsson-Sjöberg J, Amir E, Teggatz P, Barman M, Hayward M, Eastwood D, Stoel M, Zhou Y, Sodergren E, Weinstock GM, Bevins CL, Williams CB and Bos NA (2009) Enteric defensins are essential regulators of intestinal microbial ecology. Nature Immunology 11, 76.

Sanders ME, Benson A, Lebeer S, Merenstein DJ and Klaenhammer TR (2018) Shared mechanisms among probiotic taxa: Implications for general probiotic claims. Current Opinion in Biotechnology 49, 207-216.

Sassone-Corsi M, Nuccio S-P, Liu H, Hernandez D, Vu CT, Takahashi AA, Edwards RA and Raffatellu M (2016) Microcins mediate competition among Enterobacteriaceae in the inflamed gut. Nature 540, 280.

Schlee M, Harder J, Köten B, Stange EF, Wehkamp J and Fellermann K (2008) Probiotic lactobacilli and VSL\#3 induce enterocyte $\beta$-defensin 2. Clinical \& Experimental Immunology 151(3), 528-535.

Schlee M, Wehkamp J, Altenhoefer A, Oelschlaeger TA, Stange EF and Fellermann K (2007) Induction of human $\beta$-defensin 2 by the probiotic Escherichia coli nissle 1917 is mediated through flagellin. Infection and Immunity 75(5), $2399-2407$.

Schroeder BO, Wu Z, Nuding S, Groscurth S, Marcinowski M, Beisner J, Buchner J, Schaller M, Stange EF and Wehkamp J (2011) Reduction of disulphide bonds unmasks potent antimicrobial activity of human $\beta$-defensin 1. Nature 469, 419.

Scientific Advisory Committee on Nutrition (2015) Carbohydrates and health. Available at https://www.gov.uk/government/ uploads/system/uploads/attachment_data/file/445503/SACN_Carbohydrates_and_Health.pdf (accessed 1 July 2018)

Segers ME and Lebeer S (2014) Towards a better understanding of Lactobacillus rhamnosus GG-host interactions. Microbial Cell Factories 13(1), S7.

Seifert S, Bub A, Franz CMAP and Watzl B (2011) Probiotic Lactobacillus casei Shirota supplementation does not modulate immunity in healthy men with reduced natural killer cell activity. The Journal of Nutrition 141(5), 978-984.

Sekita Y, Tokita K, Tokita J, Nishiyama Y, Namatame K, Uchida K, Kushiro A and Aiba N (2015) Case report of bowel habit improvement in elderly in a nursing home by continuous intake of fermented milk products. Journal of the Japan Dietetic Association 58(6), 440-445.

Sellmann C, Priebs J, Landmann M, Degen C, Engstler AJ, Jin CJ, Gärttner S, Spruss A, Huber O and Bergheim I (2015) Diets rich in fructose, fat or fructose and fat alter intestinal barrier function and lead to the development of nonalcoholic fatty liver disease over time. The Journal of Nutritional Biochemistry 26(11), 1183-1192.

Serino M, Luche E, Gres S, Baylac A, Bergé M, Cenac C, Waget A, Klopp P, Iacovoni J and Klopp C (2012) Metabolic adaptation to a high-fat diet is associated with a change in the gut microbiota. Gut 61(4), 543-553.

Shah P, Fritz JV, Glaab E, Desai MS, Greenhalgh K, Frachet A, Niegowska M, Estes M, Jäger C, Seguin-Devaux C, Zenhausern $\mathbf{F}$ and Wilmes $\mathbf{P}$ (2016) A microfluidics-based in vitro model of the gastrointestinal human-microbe interface. Nature Communication 7, 11535.

Shida K, Sato T, Iizuka R, Hoshi R, Watanabe O, Igarashi T, Miyazaki K, Nanno M and Ishikawa F (2017) Daily intake of fermented milk with Lactobacillus casei strain Shirota reduces the incidence and duration of upper respiratory tract infections in healthy middle-aged office workers. European Journal of Nutrition 56(1), 45-53.

Shimizu-Kadota M and Sakurai T (1982) Prophage curing in Lactobacillus casei by isolation of a thermoinducible mutant. Applied and Environmental Microbiology 43(6), 1284-1287.

Shimizu-Kadota M, Sakurai T and Tsuchida N (1983) Prophage origin of a virulent phage appearing on fermentations of Lactobacillus casei S-1. Applied and Environmental Microbiology 45(2), 669-674.

Shkoporov AN, Ryan FJ, Draper LA, Forde A, Stockdale SR, Daly KM, McDonnell SA, Nolan JA, Sutton TD and Dalmasso M (2018) Reproducible protocols for metagenomic analysis of human faecal phageomes. Microbiome 6(1), 68. 
Sivan A, Corrales L, Hubert N, Williams JB, Aquino-Michaels K, Earley ZM, Benyamin FW, Lei YM, Jabri B, Alegre ML, Chang EB and Gajewski TF (2015) Commensal Bifidobacterium promotes antitumor immunity and facilitates anti-PD-L1 efficacy. Science 350(6264), 1084-1089.

Sohn J-W (2015) Network of hypothalamic neurons that control appetite. BMB Reports 48(4), 229-233.

Spadoni I, Fornasa G and Rescigno M (2017) Organ-specific protection mediated by cooperation between vascular and epithelial barriers. Nature Reviews Immunology 17, 761.

Spadoni I, Pietrelli A, Pesole G and Rescigno M (2016) Gene expression profile of endothelial cells during perturbation of the gut vascular barrier. Gut Microbes 7(6), 540-548.

Spadoni I, Zagato E, Bertocchi A, Paolinelli R, Hot E, Di Sabatino A, Caprioli F, Bottiglieri L, Oldani A and Viale G (2015) A gut-vascular barrier controls the systemic dissemination of bacteria. Science 350(6262), 830-834.

Spanhaak S, Havenaar R and Schaafsma G (1998) The effect of consumption of milk fermented by Lactobacillus casei strain Shirota on the intestinal microflora and immune parameters in humans. European Journal of Clinical Nutrition 52, 899.

Stadlbauer V, Mookerjee RP, Hodges S, Wright GAK, Davies NA and Jalan R (2008) Effect of probiotic treatment on deranged neutrophil function and cytokine responses in patients with compensated alcoholic cirrhosis. Journal of Hepatology 48(6), 945-951.

Steck N, Hoffmann M, Sava IG, Kim SC, Hahne H, Tonkonogy SL, Mair K, Krueger D, Pruteanu M and Shanahan F (2011) Enterococcus faecalis metalloprotease compromises epithelial barrier and contributes to intestinal inflammation. Gastroenterology 141(3), 959-971.

Steffensen KR and Gustafsson J-Å (2004) Putative metabolic effects of the liver X receptor (LXR). Diabetes 53(suppl 1), S36-S42.

Sudo N, Chida Y, Aiba Y, Sonoda J, Oyama N, Yu XN, Kubo C and Koga Y (2004) Postnatal microbial colonization programs the hypothalamic-pituitary-adrenal system for stress response in mice. The Journal of Physiology 558(1), 263-275.

Sur D, Manna B, Niyogi S, Ramamurthy T, Palit A, Nomoto K, Takahashi T, Shima T, Tsuji H and Kurakawa T (2011) Role of probiotic in preventing acute diarrhoea in children: A community-based, randomized, double-blind placebo-controlled field trial in an urban slum. Epidemiology \& Infection 139(6), 919-926.

Takada M, Nishida K, Gondo Y, Kikuchi-Hayakawa H, Ishikawa H, Suda K, Kawai M, Hoshi R, Kuwano Y and Miyazaki K (2017) Beneficial effects of Lactobacillus casei strain Shirota on academic stress-induced sleep disturbance in healthy adults: A double-blind, randomised, placebo-controlled trial. Beneficial Microbes 8(2), 153-162.

Takada M, Nishida K, Kataoka-Kato A, Gondo Y, Ishikawa H, Suda K, Kawai M, Hoshi R, Watanabe O and Igarashi T (2016) Probiotic Lactobacillus casei strain Shirota relieves stress-associated symptoms by modulating the gut-brain interaction in human and animal models. Neurogastroenterology \& Motility 28(7), 1027-1036.

Takeda K, Suzuki T, Shimada SI, Shida K, Nanno M and Okumura K (2006) Interleukin-12 is involved in the enhancement of human natural killer cell activity by Lactobacillus casei Shirota. Clinical \& Experimental Immunology 146(1), 109-115.

Tigchelaar EF, Zhernakova A, Dekens JAM, Hermes G, Baranska A, Mujagic Z, Swertz MA, Muñoz AM, Deelen P, Cénit MC, Franke L, Scholtens S, Stolk RP, Wijmenga C and Feskens EJM (2015) Cohort profile: LifeLines DEEP, a prospective, general population cohort study in the northern Netherlands: Study design and baseline characteristics. BMJ Open 5(8), e006772.

Tjalsma H, Boleij A, Marchesi JR and Dutilh BE (2012) A bacterial driver-passenger model for colorectal cancer: Beyond the usual suspects. Nature Reviews Microbiology 10, 575.

Toi M, Hirota S, Tomotaki A, Sato N, Hozumi Y, Anan K, Nagashima T, Tokuda Y, Masuda N and Ohsumi S (2013) Probiotic beverage with soy isoflavone consumption for breast cancer prevention: A case-control study. Current Nutrition \& Food Science 9(3), 194-200.

Tomusiak-Plebanek A, Heczko P, Skowron B, Baranowska A, Okoń K, Thor PJ and Strus M (2018) Lactobacilli with superoxide dismutase-like or catalase activity are more effective in alleviating inflammation in an inflammatory bowel disease mouse model. Drug Design, Development and Therapy 12, 3221-3233.

Tripathi P, Beaussart A, Alsteens D, Dupres V, Claes I, Von Ossowski I, De Vos WM, Palva A, Lebeer S and Vanderleyden J (2013) Adhesion and nanomechanics of pili from the probiotic Lactobacillus rhamnosus GG. ACS Nano 7(4), 3685-3697.

Tsuji H, Matsuda K and Nomoto K (2018) Counting the countless: Bacterial quantification by targeting rRNA molecules to explore the human gut microbiota in health and disease. Frontiers in Microbiology 9, 1417.

Tuohimaa A, Riipinen K-A, Brandt K and Alatossava T (2006) The genome of the virulent phage Lc-Nu of probiotic Lactobacillus rhamnosus, and comparative genomics with Lactobacillus casei phages. Archives of Virology 151(5), 947.

Tuomola EM, Ouwehand AC and Salminen SJ (1999) The effect of probiotic bacteria on the adhesion of pathogens to human intestinal mucus. Pathogens and Disease 26(2), 137-142.

Vajro P, Mandato C, Licenziati MR, Franzese A, Vitale DF, Lenta S, Caropreso M, Vallone G and Meli R (2011) Effects of Lactobacillus rhamnosus strain GG in pediatric obesity-related liver disease. Journal of Pediatric Gastroenterology and Nutrition 52(6), 740-743.

van den Broek M, De Boeck I, Claes I, Nizet V and Lebeer S (2018) Multifactorial inhibition of lactobacilli against the respiratory tract pathogen Moraxella catarrhalis. Beneficial Microbes 9(3), 429-439. 
Van den Nieuwboer M, Klomp-Hogeterp A, Verdoorn S, Metsemakers-Brameijer L, Vriend T, Claassen E and Larsen O (2015) Improving the bowel habits of elderly residents in a nursing home using probiotic fermented milk. Beneficial Microbes 6(4), 397-403.

Van den Abbeele P, Belzer C, Goossens M, Kleerebezem M, De Vos WM, Thas O, De Weirdt R, Kerckhof F-M and Van de Wiele T (2013) Butyrate-producing Clostridium cluster XIVa species specifically colonize mucins in an in vitro gut model. The ISME Journal 7(5), 949.

van Straten EME, Bloks VW, Huijkman NCA, Baller JFW, Meer HV, Lütjohann D, Kuipers F and Plösch T (2010) The liver $\mathrm{X}$-receptor gene promoter is hypermethylated in a mouse model of prenatal protein restriction. American Journal of Physiology-Regulatory Integrative and Comparative Physiology 298(2), R275-R282.

Van Puyenbroeck K, Hens N, Coenen S, Michiels B, Beunckens C, Molenberghs G, ... Verhoeven V (2012) Efficacy of daily intake of Lactobacillus casei Shirota on respiratory symptoms and influenza vaccination immune response: A randomized, double-blind, placebo-controlled trial in healthy elderly nursing home residents. The American Journal of Clinical Nutrition 95(5), 1165-1171.

Vassallo G, Mirijello A, Ferrulli A, Antonelli M, Landolfi R, Gasbarrini A and Addolorato G (2015) Review article: Alcohol and gut microbiota - the possible role of gut microbiota modulation in the treatment of alcoholic liver disease. Alimentary Pharmacology \& Therapeutics 41(10), 917-927.

Volynets V, Küper MA, Strahl S, Maier IB, Spruss A, Wagnerberger S, Königsrainer A, Bischoff SC and Bergheim I (2012) Nutrition intestinal permeability and blood ethanol levels are altered in patients with Nonalcoholic Fatty Liver Disease (NAFLD). Digestive Diseases and Sciences 57(7), 1932-1941.

Wagnerberger S, Spruss A, Kanuri G, Volynets V, Stahl C, Bischoff SC and Bergheim I (2012) Toll-like receptors 1-9 are elevated in livers with fructose-induced hepatic steatosis. British Journal of Nutrition 107(12), 1727-1738.

Wallace BD, Wang H, Lane KT, Scott JE, Orans J, Koo JS, Venkatesh M, Jobin C, Yeh L-A and Mani S (2010) Alleviating cancer drug toxicity by inhibiting a bacterial enzyme. Science 330(6005), 831-835.

Wallace TC, Francisco G, Karen M, Cabana MD, Glenn G, Eric H and Ellen SM (2011) Human gut microbiota and its relationship to health and disease. Nutrition Reviews 69(7), 392-403.

Walzer T, Dalod M, Robbins SH, Zitvogel L and Vivier E (2005) Natural-killer cells and dendritic cells: "l'union fait la force". Blood 106(7), 2252-2258.

Wampach L, Heintz-Buschart A, Fritz JV, Ramiro-Garcia J, Habier J, Herold M, Narayanasamy S, Kaysen A, Hogan AH and Bindl L (2018) Birth mode is associated with earliest strain-conferred gut microbiome functions and immunostimulatory potential. Nature Communications 9(1), 5091.

Wampach L, Heintz-Buschart A, Hogan A, Muller EL E, Narayanasamy S, Laczny CC, Hugerth LW, Bindl L, Bottu J, Andersson A, de Beaufort C and Wilmes P (2017) Colonization and succession within the human gut microbiome by archaea bacteria and microeukaryotes during the first year of life. Frontiers in Microbiology 8, 738.

Wehkamp J, Harder J, Wehkamp K, Meissner BW-V, Schlee M, Enders C., Sonnenborn U, Nuding S, Bengmark S, Fellermann K, Schröder JM and Stange EF (2004) NF- $\mathrm{KB}$ - and AP-1-mediated induction of human beta defensin-2 in intestinal epithelial cells by Escherichia coli Nissle 1917: A novel effect of a probiotic bacterium. Infection and Immunity 72 (10), 5750-5758.

Wehkamp J, Salzman NH, Porter E, Nuding S, Weichenthal M, Petras RE, Shen B, Schaeffeler E, Schwab M, Linzmeier R, Feathers RW, Chu H, Lima H, Fellermann K, Ganz T, Stange EF and Bevins CL (2005) Reduced paneth cell $\alpha$-defensins in ileal Crohn's disease. Proceedings of the National Academy of Sciences of the United States of America 102(50), 18129-18134.

Wehkamp J and Stange EF (2010) Paneth's disease. Journal of Crohn's and Colitis 4(5), 523-531.

Wichmann A, Allahyar A, Greiner TU, Plovier H, Lundén GÖ, Larsson T, Drucker DJ, Delzenne NM, Cani PD and Bäckhed F (2013) Microbial modulation of energy availability in the colon regulates intestinal transit. Cell Host \& Microbe 14 (5), 582-590.

Wiest R, Lawson M and Geuking M (2014) Pathological bacterial translocation in liver cirrhosis. Journal of Hepatology 60(1), 197-209.

Wijmenga C and Zhernakova A (2018) The importance of cohort studies in the post-GWAS era. Nature Genetics 50(3), 322-328.

Wolk K, Kunz S, Witte E, Friedrich M, Asadullah K and Sabat R (2004) IL-22 increases the innate immunity of tissues. Immunity 21(2), 241-254.

Wong S, Jamous A, O'Driscoll J, Sekhar R, Weldon M, Yau CY, Hirani SP, Grimble G and Forbes A (2014) A Lactobacillus casei Shirota probiotic drink reduces antibiotic-associated diarrhoea in patients with spinal cord injuries: A randomised controlled trial. British Journal of Nutrition 111(4), 672-678.

Wright K, Wright H and Murray M (2015) Probiotic treatment for the prevention of antibiotic-associated diarrhoea in geriatric patients: A multicentre randomised controlled pilot study. Australasian Journal on Ageing 34(1), 38-42.

Wuyts S, Wittouck S, De Boeck I, Allonsius CN, Pasolli E, Segata N and Lebeer S (2017) Large-scale phylogenomics of the Lactobacillus casei group highlights taxonomic inconsistencies and reveals novel clade-associated features. MSystems 2(4), e00061-17. 
Yasuda E, Serata M and Sako T (2008) Suppressive effect on activation of macrophages by Lactobacillus casei strain Shirota genes determining the synthesis of cell wall-associated polysaccharides. Applied and Environmental Microbiology 74(15), 4746-4755.

Younossi ZM (2018) The epidemiology of nonalcoholic steatohepatitis. Clinical Liver Disease 11(4), 92-94.

Zeissig S and Blumberg RS (2014) Life at the beginning: Perturbation of the microbiota by antibiotics in early life and its role in health and disease. Nature Immunology 15(4), 307.

Zhernakova A, Kurilshikov A, Bonder MJ, Tigchelaar EF, Schirmer M, Vatanen T, Mujagic Z, Vila AV, Falony G and Vieira-Silva S (2016) Population-based metagenomics analysis reveals markers for gut microbiome composition and diversity. Science 352(6285), 565-569.

Zhou D, Pan Q, Shen F, Cao H-X, Ding W-J, Chen Y-W and Fan J-G (2017) Total fecal microbiota transplantation alleviates high-fat diet-induced steatohepatitis in mice via beneficial regulation of gut microbiota. Scientific Reports 7(1), 1529.

Zitvogel L, Daillère R, Roberti MP, Routy B and Kroemer G (2017) Anticancer effects of the microbiome and its products. Nature Reviews Microbiology 15, 465.

Cite this article: Lockyer S., Aguirre M., Durrant L., Pot B., and Suzuki K. 2020. The role of probiotics on the roadmap to a healthy microbiota: a symposium report. Gut Microbiome, 1, e2, 1-30. https://doi.org/10.1017/gmb.2020.2

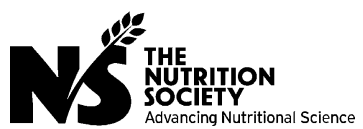

